\title{
Infant Brain
}




\section{Abstract}

30 Faces are a rich source of social information. How does the infant brain develop the ability to

31 recognize faces and identify potential social partners? We collected functional magnetic

32 neuroimaging (fMRI) data from 49 awake human infants (aged 2.5-9.7 months) while they watched

33 movies of faces, bodies, objects, and scenes. Face-selective responses were observed not only in

34 ventral temporal cortex (VTC) but also in superior temporal sulcus (STS), and medial prefrontal

35 cortex (MPFC). Face responses were also observed (but not fully selective) in the amygdala and

36 thalamus. We find no evidence that face-selective responses develop in visual perception regions

37 (VTC) prior to higher order social perception (STS) or social evaluation (MPFC) regions. We

38 suggest that face-selective responses may develop in parallel across multiple cortical regions. Infants'

39 brains could thus simultaneously process faces both as a privileged category of visual images, and as

40 potential social partners. 


\section{Introduction}

From birth, infants see faces often [1-3], prefer to look at faces more than non-face visual stimuli [4-9], and readily distinguish a familiar face from an unfamiliar one [10,11]. Infants' brains visually process faces as a distinct object category [12] but it is not known when in development infants' brains begin to process the social attributes of faces. In adult brains, perception of faces not only evokes activity in face-selective visual regions [13-15] but also in higher-order brain regions that represent multi-modal social perception and evaluation [16-18]. This paper addresses the open, and hotly debated question, of how this suite of face-selective regions develop. We test two contrasting hypotheses: (1) face-selective responses develop sequentially, with visual perception regions responding selectively to faces earlier in development than higher-order social regions, or (2) face-selective responses emerge in such that perceptual and social regions come to represent the visual category and social meaning of faces simultaneously. Here we use functional magnetic resonance imaging (fMRI) data from a large group of awake human infants to test whether faceselective responses in social regions emerge later in development than visual perceptual regions.

Serial Hypothesis of Cortical Development

One prominent hypothesis, which we call the "Serial Hypothesis" of development, holds that distinct brain regions become face-selective in a feed-forward developmental sequence (Figure 1a; for recent reviews see: [19-21]). On this view, face-selective responses first emerge in subcortical regions as a response to the salient visual properties of faces, then in higher-level visual cortex as infants gain experience looking at faces, and finally in higher-order social cognition regions as infants learn the connection between faces and social value. By analogy to the conspecific detection mechanism in newly hatched chicks [22], the first brain region to respond distinctively to faces is likely to be subcortical. This subcortical region would contain a rough template of face-like images (e.g., high contrast shapes with an upper field bias), which would then drive infants to look at faces. Because subcortical regions are small and deep in the brain, they are very hard to measure in human or non-human primate infants, but plausible sites for an innate subcortical face template in primates include the superior colliculus, pulvinar, and/or amygdala [6].

Next, the frequent appearance of face-like images in infants' visual experience would drive bottom-up, self-organizing specialization of regions in the cortical visual system [20,23]. The Serial Hypothesis supposes that high-level visual regions initially self-organize along low-level features

71 (e.g., retinotopy, spatial frequency, curvilinearity), called a proto-organization [20]. For example, the area that becomes the fusiform face area (FFA) would acquire a face-selective response profile 
73 gradually, as infants gain visual exposure to the combination of curvy, low spatial frequency

74 environmental input characteristic of faces [24]. In line with this hypothesis, adult face-selective

75 regions respond more to images with curvilinear features than images with rectilinear features, even

76 in the absence of faces $[25,26]$ and macaques raised without exposure to faces do not have face-

77 selective responses that can be measured with fMRI [27].

78 Finally, once high-level visual regions have formed a visual category of faces, even higher

79 order brain regions would then be able to associate faces with multi-modal information about social

80 meaning and emotional value. In adults, the social and emotional meaning of faces are encoded in

81 (among other regions) superior temporal sulcus (STS) and medial prefrontal cortex (MFPC). The

82 response profiles of these regions are distinct in adults from the perceptual face responses in FFA.

83 The STS has been implicated in a variety of social perception tasks [17] including facial movement

84 [28], social interaction perception [29], voice perception [30,31], and multimodal face and voice

85 perception [32,33]. The MPFC is specifically involved in abstract social and emotional processes,

86 such as social evaluation [34-36], self-referential processing [35,37-41], and emotion attribution

$87 \quad[16,35,42-47]$.

The Serial Hypothesis of development predicts that responses to faces in STS and MPFC would develop later, potentially much later, than category selective regions in VTC [20-22]. One

90 source of this prediction is the evidence that anatomical development proceeds from primary

91 sensory areas to association cortices [48-53] (for review see: [54]). Signatures of cortical maturation

92 including expansion [55], increased sulci depth [56], and myelination [57-59] occur in primary

93 sensory areas earlier in development than association areas. Not only does anatomical development

94 of the brain occur in series, but signatures of neural function such as glucose metabolism [60] and

95 synaptogenesis [61] reach their peak in primary sensory areas prior to association areas. Perhaps

96 most surprisingly, new neurons are still migrating and being integrated into PFC well into the second

97 year of life [62] - a process that completes in primary sensory areas around the time of birth [63].

98 This evidence has led to the hypothesis that due to the structural immaturity of association cortex,

99 functions associated with those regions in adults are not yet present in infants. Yet, it is equally

100 plausible that rather than anatomical maturation preceding neural function, perhaps neural function

101 and anatomical maturation are intrinsically reciprocal in brain development. 


\section{a) Serial Hypothesis}

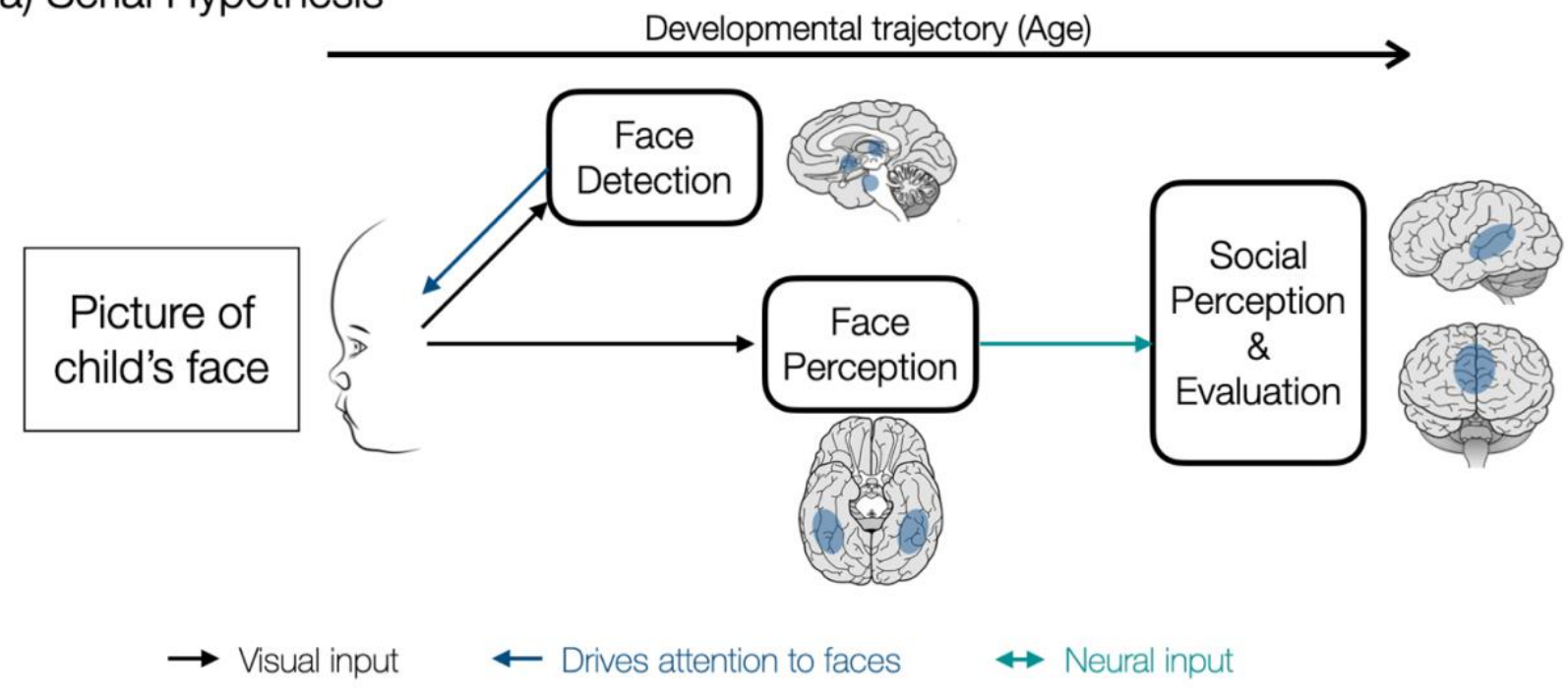

b) Parallel Hypothesis
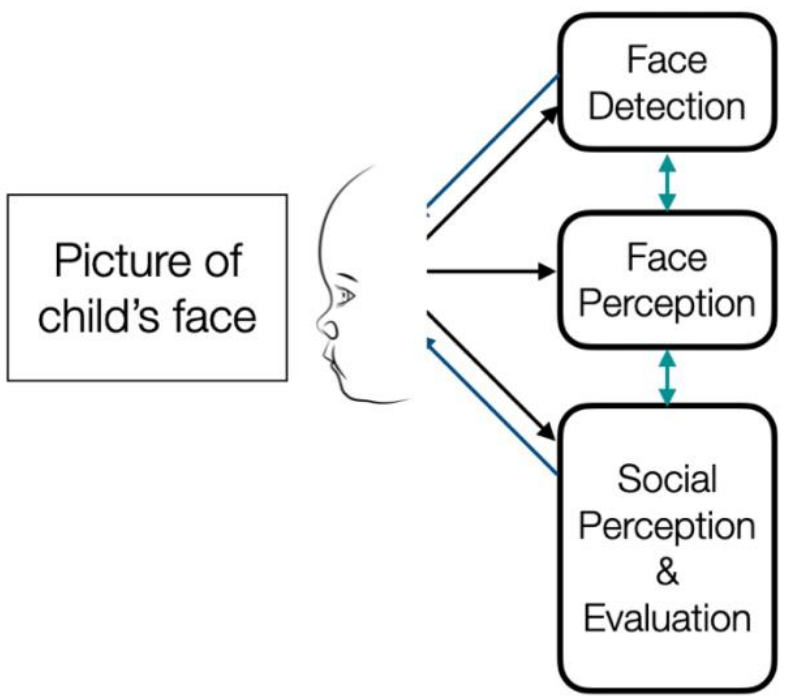

c) Infant fMRI

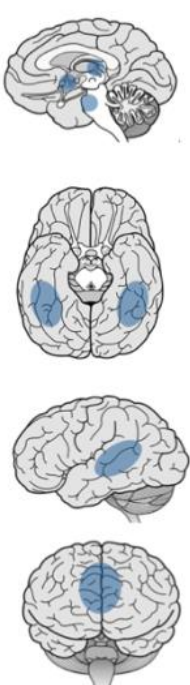

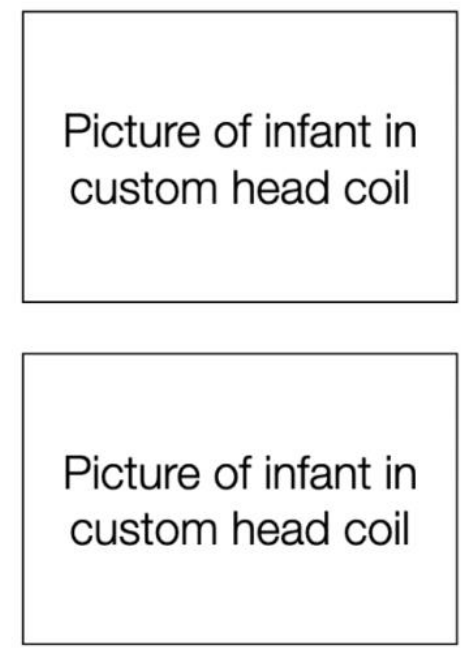

\section{Figure 1. Alternative hypotheses make different predictions about when face-selective} responses emerge in infants' brains. a) The Serial Hypothesis predicts that the earliest faceselective responses arise in an innate subcortical face-template, which drives infants to attend to face-like images. Visual experience with faces then causes self-organization of face-selective responses in ventral-temporal cortical regions, like FFA. Subsequently, higher-order regions like STS and MPFC can associate face shapes with emotional and social meaning. b) Alternatively, the Parallel Hypothesis proposes that from early in infancy, infants' attention to faces is driven by both perceptual and socio-emotional processes; and that face-selective responses in STS and MPFC arise simultaneously with, and potentially provide input to, perceptual representations of faces in ventraltemporal cortex. c) For each MRI visit, swaddled infants were placed in a custom 32-channel infant head coil. Movies were projected in a mirror over their eyes. Example face stimuli pictured (a-b). Blue areas were added to brain images created by Milan Vukelić and available for Public License at: https://www.behance.net/gallery/5399443/BRAINS-028cognitive-neurosciences\%29. Photo credit for images in c to Caitlin Cunningham Photography. 


\section{Parallel Hypothesis of Cortical Development}

By contrast to the Serial Hypothesis of development, we propose a Parallel Hypothesis, in

120 which responses to the social meanings and emotional value of faces (by reverse inference in STS

121 and MPFC, respectively) emerge just as early in development as perceptual responses to faces in

122 FFA (Figure 1b). Substantial behavioral and neural evidence supports this hypothesis. Behaviorally, 123 infants' active attention to faces cannot be fully explained by a face-template or preference for face-

124 like images. Neonates and young infants do not merely prefer to look at faces over other stimuli, but

125 choose to look at some faces more than others, based on both visual (e.g., skin tone, sex, facial

126 expression) and non-visual (e.g., speaker language, prosody, social behavior) properties [11,64-72].

127 These behavioral data suggest that infants' brains represent not just the perceptual form, but also the

128 social meaning and emotional value of faces. Consistent with the predictions from behavioral data,

129 studies using functional near-infrared spectroscopy (fNIRS), electroencephalography (EEG), and

130 positron emission topography (PET) in human infants show responses to faces in the superior

131 temporal sulcus (STS) as early as a few days after birth [73-80] and in the medial prefrontal cortex

132 (MPFC) by 5-months (the earliest that has been reported) [74,77,80-82].

133 However, no previous study has directly tested whether face-selective responses in human

134 infants emerge in subcortical regions followed by visual higher-level visual cortex, followed by

135 social-emotional regions, as predicted by the Serial Hypothesis, or simultaneously across these

136 regions, as predicted by the Parallel Hypothesis. The main limitation is that responses in subcortical

137 and ventral visual regions cannot be measured using surface-based neuroimaging techniques like

138 fNIRS and EEG.

\section{Current study}

For the current study, we analyzed fMRI data from 49 infants (Figure 1c) while they watched

141 videos of faces, bodies, objects, scenes, and an abstract baseline. Infants ranged in age from 2 to 9

142 months, meaning that the oldest infants had three times as much visual experience as the youngest

143 ones. Thus, these data allow us to test distinctive predictions of the two hypotheses. The Serial

144 Hypothesis makes three predictions. First, infants as a group may not yet have any face-selective

145 responses in the purported latest developing regions (STS and MPFC). Second, face-selective

146 responses should be correlated with age, particularly in cortical regions. In visual perceptual regions

147 (e.g., FFA), face-selective responses should increase with infants' age and visual experience; and if

148 there is any face-selective response in STS or MPFC, it should be more selective in the older infants. 
Third, a subset of infants (plausibly, the youngest ones) should have face-selective responses in FFA but not yet in STS and MPFC.

Conversely, the Parallel Hypothesis makes a different set of predictions. If face-selective

152 responses appear early and simultaneously across multiple brain areas (Figure 1b), then infants as a

153 group should show face-selective responses in subcortical, visual perceptual, and social-emotional

154 regions. Second, face-selective responses should either be present in all infants from the earliest ages

155 or increase simultaneously in all regions. Third, any subset of infants who have face-selective

156 responses in FFA should also have face-selective responses in STS and MPFC.

\section{Results}

\section{Face-selective responses observed in infant STS and MPFC}

One group of infants was scanned on an older infant coil [83] with a sinusoidal acquisition

160 sequence [84] (Coil 2011; $\mathrm{n}=26$ ) and a second group of infants was scanned on a newer infant coil

161 [85] with a standard acquisition sequence (Coil 2021; $\mathrm{n}=23$ ), resulting in higher SNR (see Methods).

162 For the first set of analyses, we treat the two datasets as independent tests of the hypothesis.

As the Serial and Parallel Hypotheses make contrasting predictions for whether infants as a

164 group will have face-selective responses in the STS and MPFC, we first look in these regions. In a

165 group random effects analysis, we observed responses to faces that were greater than the response

166 to the average of non-face conditions in bilateral STS and MPFC, in both the Coil 2011 data and the

167 Coil 2021 data (Figure 2).

168 To test whether face responses in STS and MPFC are significantly larger than responses to 169 each control condition (i.e., are "face selective" [15]), we used a functional region of interest (fROI)

170 analysis. We identified the top 5\% of voxels that responded more to faces than the average of the

171 other categories within each broad region in individual infants and then extracted responses in those

172 voxels to all four conditions in independent, left-out data from the same infant (see Methods). In the

173 Coil $2011 \mathrm{fROI}$ analysis (Figure 2a, n=18), STS and MPFC face responses were significantly and

174 substantially greater than the response to each of the three other stimulus categories (all $P_{s}<0.02$;

175 Table S1). These results were replicated in the Coil $2021 \mathrm{fROI}$ analysis ( $\mathrm{n}=20$, Figure 2b; all

$176 P_{s}<0.003$; Table S1) and when data were combined across both coils ( $\mathrm{n}=38,35$ individuals; Figure

177 3a-b; all $P_{s}<0.00008$; Table S1). 
a) Coil 2011 dataset
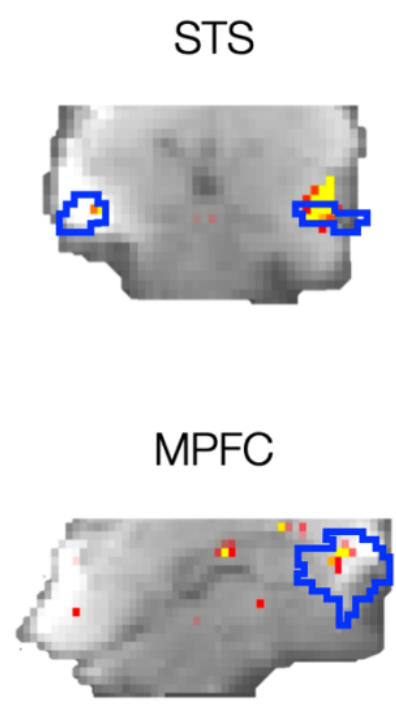
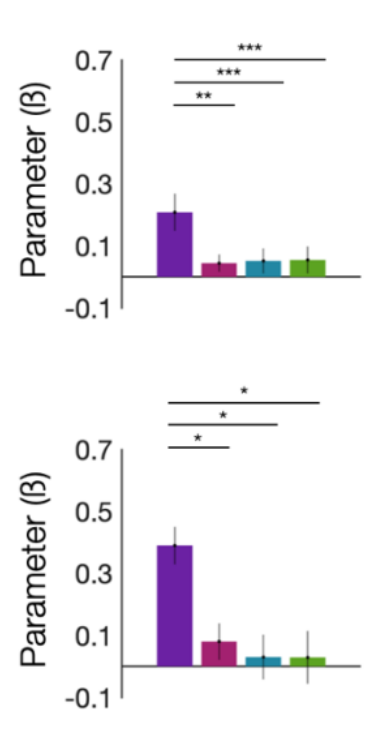

b) Coil 2021 dataset
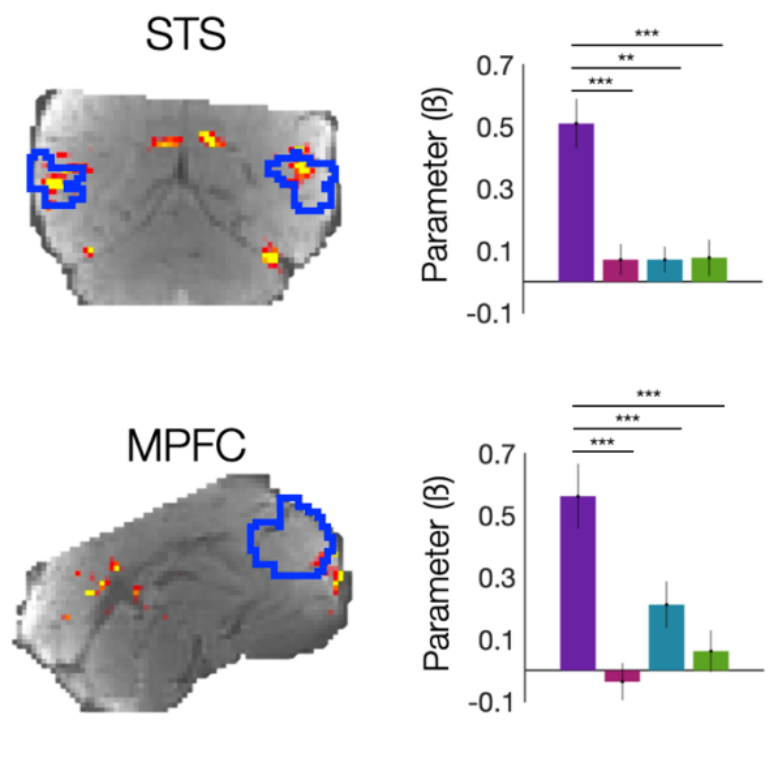

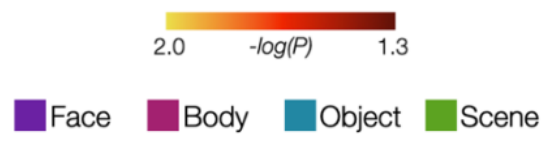

Figure 2. Face responses in infant STS and MPFC are selective. Group whole brain random effects analysis of Coil 2011 data $(a ; n=26)$ and Coil 2021 data $(b ; n=23)$ revealed face responses (faces $>$ (bodies+objects+scenes)) in both STS (top) and MPFC (bottom). Note that the precise anatomical location of STS and MPFC activations between Coil 2011 and Coil 2021 datasets cannot be directly compared due to differences in distortion and resolution (Figure S2). Group maps are displayed on representative functional images from each coil; threshold $P<0.05$, uncorrected, for visualization purposes. Cortical area outlined blue represents the anatomical search space. An fROI analysis of Coil 2011 ( $n=20,18$ individuals) revealed face responses (purple) that were significantly greater in independent data than the response to bodies (pink) objects (teal) and scenes (green) in STS and MPFC. These results were replicated in the Coil 2021 dataset (b). Symbols: ${ }^{*} P<0.05$; ${ }^{* *} P<0.01 ;{ }^{* *} P<0.001$. Error bars indicate within-subject SE [86].

With the Coil 2011 and Coil 2021 datasets combined, we next conducted the same fROI analyses varying the number of voxels selected from the top $1 \%$ of voxels to $100 \%$ of voxels in each of the parcels, and tested responses in held out data. In both STS and MPFC, no matter how large the subset of voxels selected, the observed face response was significantly greater than the response to each non-face condition (Figure 3a-b) indicating face-selective responses in infant STS and MPFC are robust and do not depend on the threshold for fROI definition.

$$
\text { Thus, infants as a group have face-selective responses in STS and MPFC, regions that }
$$
represent social meaning and emotional value in adults. The presence of face-selective responses in 
200 serially, the process must occur within the first few months of life.

Parcels
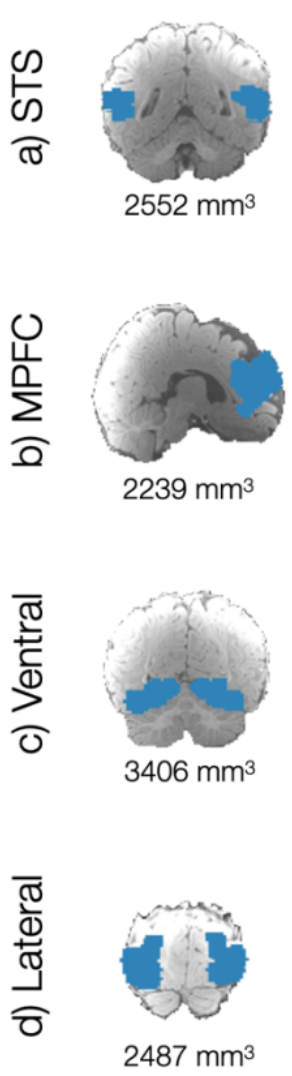

Combined fROI
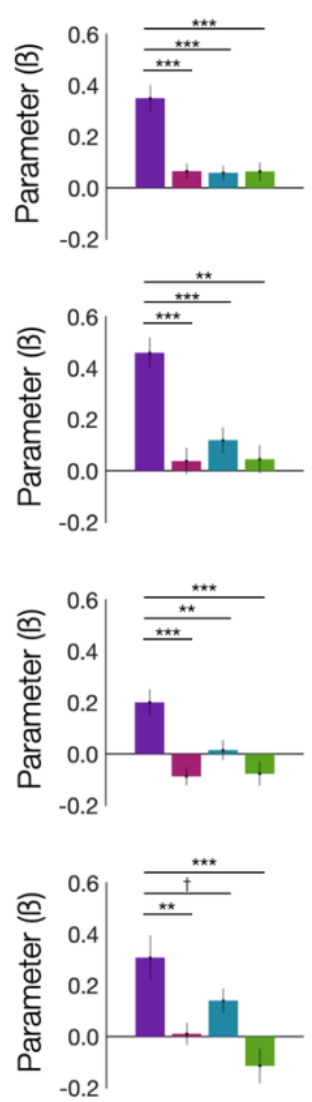

Sliding Window
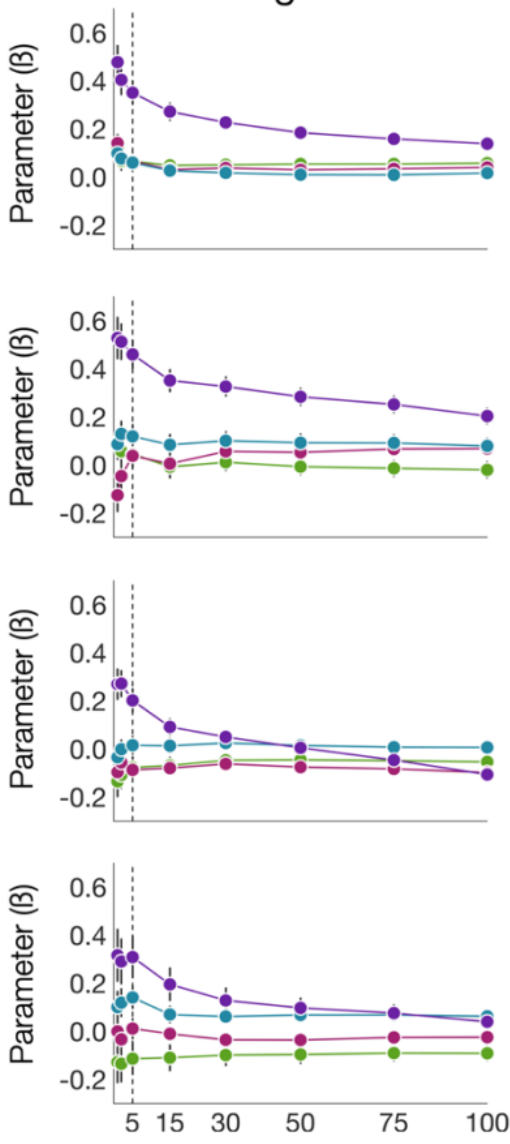

Top N \% Voxels
Age Analysis
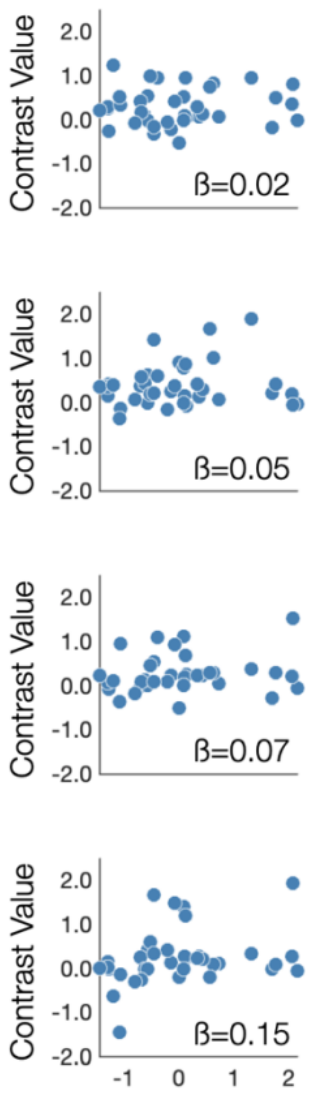

Age (Z-Score)

Search Space

Face

Body

Object Scene

Figure 3. Cortical face-selective responses are not correlated with age. In fROI analyses collapsed across Coil 2011 and Coil 2021 datasets (n=38, 35 individuals), we used four large anatomical search spaces (first column, blue, projected onto an infant anatomical image) of STS (a), MPFC (b), ventral-temporal cortex (c), and lateral-occipital cortex (d). Bar charts show the average response across participants in each fROI (top 5\% of voxels) to each stimulus category (compared to baseline) in data independent of that used to define the fROI. Error bars indicate within-subject SE [86]. Symbols used to report one-tailed statistics from linear mixed effects models: ${ }^{\dagger} P<0.1$; ${ }^{*} P<0.05 ;{ }^{* *} P<0.01 ;{ }^{* * *} P<0.001$. Line graphs show selectivity analysis with different proportions of voxels selected with the average response in independent data for faces (purple), bodies (pink), objects (teal), and scenes (green). The vertical dashed line marks the top 5\% and corresponds to the bar charts. Error bars are standard error of the mean. The scatter plots show that the contrast value (the difference between the face response and the average response to all non-face conditions) for each fROI was not correlated with age (all $P_{s}>0.19$ ). 


\section{Infants' cortical responses to faces were not correlated with age}

The two hypotheses make contrasting predictions for whether face-selective responses in cortical regions should increase with age and visual experience. We tested these predictions in two visual regions (FFA and OFA) and in two social-emotional regions (STS and MPFC). To maximize the potential that we would be able to detect changes with age and experience, we combined the Coil 2011 and Coil 2021 datasets. Importantly, the amount of low-motion data included from each infant was not correlated with age (Fig. S1).

First, we confirmed that there is a selective response to faces in the visual regions of these infants (see [12], for a complementary analysis of Coil 2021 dataset alone in FFA- and OFA-specific parcels). To account for differences in distortion between Coil 2011 and Coil 2021 datasets (See Fig. included the location of the OFA (lateral parcel; see Methods). In an fROI analysis ( $\mathrm{n}=38$ datasets from 35 infants), the face response in the ventral parcel (Figure 3c; Table S1) was substantially and significantly larger than the response to each of the non-face conditions (all $P_{s}<0.005$ ). In the lateral parcel (Figure 3d; Table S1), we found weak evidence for a face-selective response (all $P_{s}<0.06$ ).

Next, we checked whether the difference between responses to face and non-face stimuli increased with age in any cortical region. In a linear mixed effects (LME) analysis with age as a predictor and contrast value (i.e., the response to faces minus the average response to non-faces conditions) as the dependent variable (Figure 3c-d, last column), infants' age did not predict the contrast value in either of the visual regions (LME, all $P_{s}>0.2$; Table S2). Similarly, there was no effect of age on the contrast value in either STS or MPFC parcels (all Ps>0.5; Table S2).

Thus, we did not find evidence that face-selective responses in cortical regions increase with age. Instead, face-selective responses in both visual and social-emotional regions are relatively

242 constant between ages 2 and 9 months in all regions tested.

243 No subset of infants showed face-selective responses in subcortical and visual regions but 244 not social-emotional regions.

The Serial Hypothesis distinctively predicts that a subset of infants (plausibly, the youngest

246 ones) should have face-selective responses in subcortical regions and FFA, but not yet in STS and

247 MPFC. By contrast, the Parallel Hypothesis predicts that any subset of infants who have face-

248 selective responses in FFA should also have face-selective responses in STS and MPFC. We tested

249 these predictions in four complementary ways. 
First, we considered the full sample collected with Coil 2021, because these data had the fewest distortions and thus provided the best measurements in ventral visual and subcortical regions.

252 Thus, in these infants we tested whether subcortical face-responses emerge earlier than ventral visual

253 regions, and whether ventral visual face responses emerge earlier than STS or MPFC. Group

254 random effects of the Coil 2021 dataset did not reveal subcortical responses to faces when compared

255 to the average of the other conditions (see Fig S3 for whole brain analyses of Coil 2011 data);

256 however fROI analyses are more sensitive.

a) Subcortical

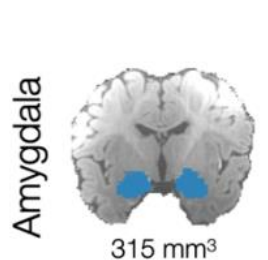

$315 \mathrm{~mm}^{3}$
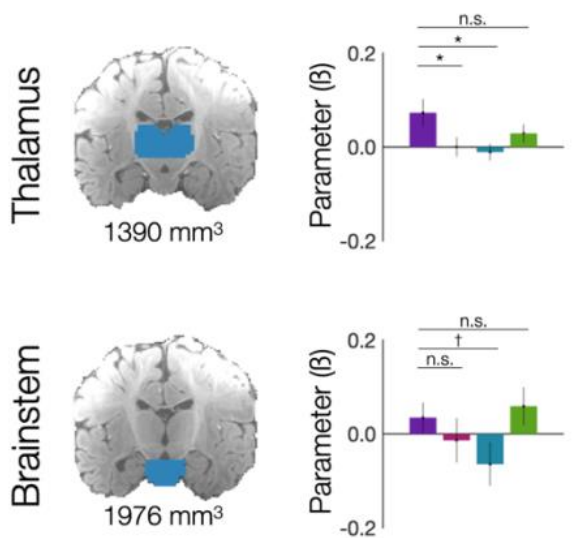

Search Space

Face

Body

Object

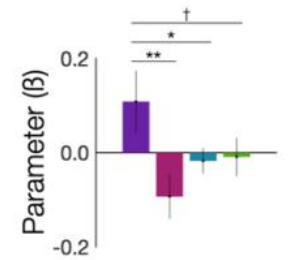

257

258

259

260

261

262

263

264

265

266

267

268

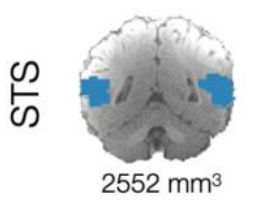

b) 2.5-4.6 Months

c) Best FFA
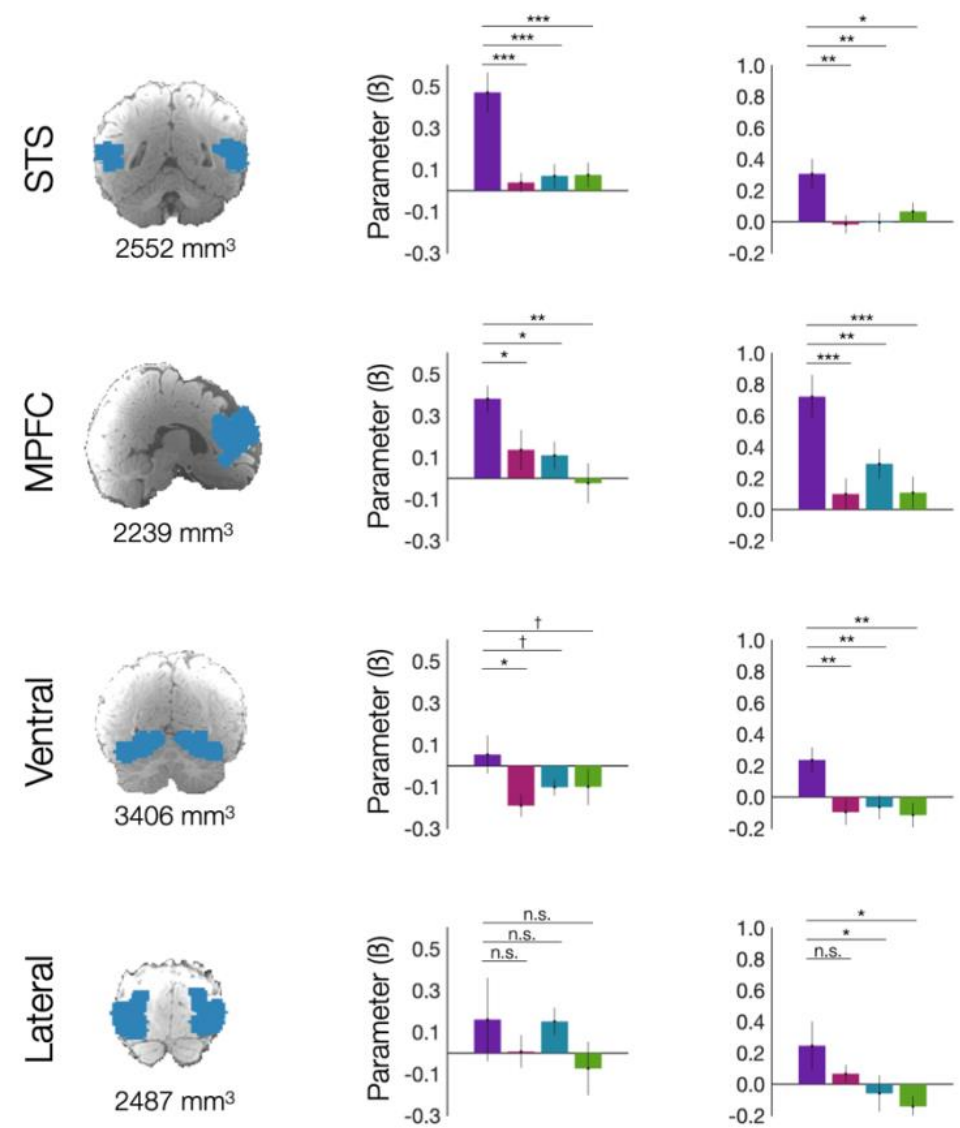

Figure 4. All subsets of infants have face-selective responses in STS and MPFC. (a) An fROI analysis of subcortical areas in infants measured in the Coil 2021 dataset revealed that the face response (purple) in the amygdala (a, top) and thalamus (a, middle) was significantly greater than the response to bodies (pink) and objects (teal) but not statistically different than the response to scenes (green). In the brainstem of these infants (a, bottom), no face-selective response was detected. (b) In an fROI analysis of all infants younger than 5.0 months, both STS and MPFC had face-selective responses, the ventral parcel had a marginally face-selective response, and the lateral parcel had no face-selective response. (c) In the 10 infants with the greatest contrast value (response to faces minus the average response to non-face conditions) in the FFA, both STS and MPFC had face selective regions, while the lateral parcel had a region that responds significantly more to faces than objects or scenes, but not bodies. Error bars indicate within-subject SE [86]. Symbols used to report 
one-tailed statistics from linear mixed effects models: ${ }^{\text {n.s. }} P>0.1 ;{ }^{\dagger} P<0.1 ;{ }^{*} P<0.05 ;{ }^{* *} P<0.01$;

We defined parcels to search for subcortical responses in superior colliculus, amygdala, and thalamus. The superior colliculus, a structure found in the brainstem, is thought to increase the salience of face-like images and thus drive infants' face looking behavior [20,22]. To search for the (very small) superior colliculus, we used our fROI method within an anatomically defined parcel covering the brainstem (Figure 4a; Table S1). While the brainstem contains a region responding numerically more to faces than to objects $(P=0.06)$, it was not statistically different than the response to either bodies $(P=0.2)$ or scenes $(P=0.6)$. The amygdala and thalamus are two other plausible sites for the putative face template. An fROI analysis (Figure 4a; Table S1) revealed weak evidence for face-selective responses in the amygdala (all $P s \leq 0.06)$ and the thalamus ( $P s \leq 0.11)$. In the same group of infants (Coil 2021 data), we observed face-selective responses in the ventral (all $P_{s}<0.001$ ) and lateral parcels (all $P_{s}<0.03$ ) as well as STS and MPFC parcels (reported above; Figure 2). These differences between regions were not due to differences in temporal signal-to-noise ratio (tSNR): subcortical, STS, and ventral parcels had a higher tSNR than MPFC and lateral parcels (Figure S4). In the Coil 2021 dataset alone, age was not a good predictor of contrast magnitude in any of the cortical parcels $(\mathrm{MPFC} \beta=0.03, P=0.9$; STS $\beta=-0.01, P=0.9$; Ventral $\beta=0.12, P=0.3$; Lateral $\beta=0.21$, $P=0.3)$ or the thalamus $(B=0.04, P=0.8)$ but was a marginal predictor of contrast magnitude in the brainstem $(\beta=0.07, P=0.09)$ and amygdala $(\beta=0.12, P=0.1)$. Thus, we find no evidence that faceselective responses emerge earlier in subcortical than in cortical regions, or earlier in visual perception regions than in social-emotional regions, in the Coil 2021 dataset.

Second, we considered just the youngest infants in our combined sample, those less than 5.0 293 Figure 4b; Table S3), we found weak evidence for a face-selective response in the ventral parcel (all $294 P s<0.09$ ) but not the lateral parcel (all $P_{s}>0.1$ ). Yet both the STS and MPFC also exhibited face 295 responses that were substantially and significantly greater than the response to each of the non-face 296 conditions (all $P s \leq 0.03$ ). Taken together, there was no evidence that visual perception regions exhibit more robust face-selective responses than social-emotional regions in the youngest infants. 
Fourth, in a final effort to determine whether the FFA develops before the STS and/or MPFC, we randomly sampled a subset of 15 infants and tested whether FFA, STS and/or MPFC showed a face-selective response. Of 2500 random sub-samples (Figure S5), all three fROIs had face-selective responses in 36.8\% (919 instances) of subsamples while $0.9 \%$ (23 instances) of subsets showed no face-selective response in any region. In 1.2\% of subsets (31 instances), infants had faceselective responses in VTC but neither STS or MPFC, whereas face-selective responses in STS and/or MPFC but not VTC occurred in 48.5\% (1212 instances) of subsets. Thus, subsets of infants who have face-selective responses in VTC but not STS or MPFC are very rare and nonrepresentative. Taken together, these results indicate that face-selective responses in visualperceptual regions do not emerge prior to face-selective responses in higher-order social-emotional

312 regions.

\section{Discussion}

Here we tested two alternative hypotheses about the development of face-selective responses in human cortex. Contrary to the predictions of the Serial Hypothesis, we found no evidence that face selectivity emerges sequentially in subcortical regions, followed by ventral visual regions, followed by "higher order" social and emotional regions. Specifically, we found evidence for face-selective responses in STS and MPFC across our dataset and these responses were not correlated with age. Most tellingly, we did not observe any evidence for a subset of infants with faceselective responses in FFA but not in STS and MPFC. These results, however, are consistent with the Parallel Hypothesis, which proposes that face-selective responses emerge simultaneously across

322 perceptual and social-emotional regions.

We note several limitations of the current study. Although we failed to find a correlation

324 between infants' age and the magnitude of face-selective responses in any region, it is possible that a true correlation was masked by the variability of data quality across infants. Awake infants are a very

326 challenging population for fMRI scanning. Using dynamic stimuli and custom-built infant-sized

327 head coils $[83,85]$, we acquired fMRI data from a large group of young infants [12], but inevitably,

328 each infant yielded a different amount of usable data. Because the amount of data per infant was low

329 (though not correlated with age), the estimate of face selectivity in each individual infant is noisy.

330 Also, the age range we tested constituted a three-fold increase in visual experience but was still small 331 relative to the human lifespan. The youngest infants who successfully participated were already 2

332 months old, and the oldest infants were only 9 months old. So, face-selective responses in cortical 333 regions may increase with age prior to age 2 months, or after 9 months, or with a very gradual slope 
that requires more data to detect. For these reasons, our failure to find a correlation between age and face selectivity is only weak evidence against the Serial Hypothesis.

The stronger evidence against the Serial Hypothesis was the finding that no subset of infants

337 in this population had face-selective responses in FFA but not STS or MPFC. One possible

338 limitation of this analysis is that the temporal signal-to-noise ratio (tSNR) and spatial distortions of

339 the images were not homogeneous across the brain. For example, the subcortical regions, which are

340 anatomically smaller, were much more distorted in the Coil 2011 dataset than the Coil 2021 dataset.

341 The hint of face-selective responses in the amygdala and thalamus in the Coil 2021 dataset is

342 intriguing but should be confirmed in future studies. We did not have enough data to test whether

343 subcortical regions had face-selective responses in the youngest infants, as predicted by the Serial

344 Hypothesis. On the other hand, consistent with the Parallel Hypothesis, nearly every subset of

345 infants we checked, including just the youngest infants (2.5-4.6 months), had face-selective

346 responses in STS and MPFC.

\section{Potential Functions of STS and MPFC in Infancy}

What functions might STS and MPFC be serving in young infants? For simplicity of

349 argument, we have up to this point treated STS and MPFC as part of a single class of "higher order"

350 regions that respond to social-emotional face features. However, these regions are anatomically

351 distant from each other and associated with different functions in adults. The STS is implicated in

352 social perception, specifically in representing the meaning of facial movements. The MPFC is

353 implicated in social evaluation, representing the value of a social stimulus or event with respect to

354 oneself or others. From behavioral evidence, it is plausible that infants engage in both kinds of social

355 cognition; and from (limited) fNIRS evidence, it is plausible that the STS and MPFC serve

356 analogous functions in infants to those they serve in adults.

For example, in adults a region of STS responds more to dynamic faces and voices than any

358 other stimulus, including still faces $[17,87]$. Infants prefer to look at dynamic faces more than still

359 faces [88,89], and in studies using fNIRS, channels near STS in infants responds more to dynamic

360 faces compared to dynamic objects or scenes [74,76,90,91]. Another region of STS in adults

361 responds to cues of animacy and social interaction in amorphous shapes or point-light display [29].

362 Infants use the same cues to identify agents and interpret actions in behavioral experiments [92-96],

363 and an fNIRS channel near STS responded to point light displays of face movement compared to

364 scrambled motion [75,97]. Thus, it is plausible that in infants and adults, regions of STS are

365 responsible for encoding other people's facial and bodily movements as meaningful actions. 
By contrast, in adults MPFC plays a distinct role from the STS. Observing social relationships, inferring others' emotions, and engaging in self-relevant tasks activate areas of MPFC [33-46]. Substantial behavioral evidence indicates that infants evaluate social stimuli in terms of their valence and self-relevance. Infants prefer to look at smiling faces and prosocial agents more than neutral, negative, or anti-social faces and agents $[68,94,98,99]$ and, self-relevant faces such as those that match the race or gender of an infant's primary caregiver, garner longer looking times $[67,69,100-104]$. Infants also have a preference for people that sing the same song [105] or speak the same language [71] as their primary caregiver. These behavioral capacities may be at least in part

374 supported by MPFC. FNIRS channels over infant MPFC respond more to smiling faces compared 375 to neutral faces [106,107], and to people that appear to engage directly with the infant by using a 376 direct gaze [81,82], playing hand games [79], or speaking in an infant-directed manner [108]. Taken 377 together, these results provide evidence that infant MPFC, like adult MPFC, preferentially responds 378 to valued, emotional, and self-relevant social stimuli.

\section{Process of Parallel Cortical Development}

In summary, we argue that face-selective responses may emerge in parallel during infancy in

381 both perceptual and higher-order association cortices. In adults, these brain regions have functions

382 that range from detection and recognition of facial identity (e.g., FFA) to perception of facial

383 movement and expression (STS) to the extracting the emotional meaning and value of the social

384 interaction (MPFC). How could face selectivity emerge in parallel across all of these regions? One

385 possibility is that even prior to maturation of sensory areas, social interactions elicit a reward

386 response which drives young infants to attend to pro-social, self-relevant aspects of their

387 environment. Under this framework, seeing engaging human faces, hearing self-relevant voices, and

388 pro-social touch would activate infants' reward network, resulting in increased attention to socially

389 relevant stimuli. In support of this hypothesis, infant STS responds to social perception in the 390 auditory [79,91,109,110], visual [74,76,90,91], and tactile [111] domains while MPFC is part of the 391 reward network [112-115] and responds to socially self-relevant environmental cues in infants

392 [79,81,82,106-108]. In infants, affective touch enhances infants' attention to faces [116] and

393 increases functional coupling between STS and MPFC [117], while auditory language modulates

394 activity in STS and MPFC [110,118]. Social perception and interaction through touch and audition

395 begins earlier and is more sustained in neonates' early experiences than visual input, in part because

396 of neonate's limited visual acuity. Thus, social experience in non-visual modalities could prime and

397 potentiate the receptivity of STS and MPFC to faces, particularly those associated with infant- 
directed speech or touch. In this way, social reward could drive infants' preferences to look at familiar, friendly, or socially valued people, shaping the input received by visual face-perception regions. On this view, during infancy, face perception in FFA, social perception in STS and social

401 evaluation in MPFC may have reciprocal and mutually reinforcing connections. The consequence of

402 such connections would be simultaneous, parallel development of face-selectivity in all of these 403 cortical regions.

The finding that MPFC has functionally specific responses in infancy also has implications for broader theories of cortical development. By anatomical metrics like myelination and cortical 406 thinning, prefrontal cortices are the slowest cortical areas to mature. Anatomical development of 407 PFC is implicated in late-developing cognitive functions such as executive function and language 408 [48-54,119-121]. Thus, many researchers have assumed the prefrontal cortex is not a major player

409 in cognitive function during the earliest stages of development. In contrast, our results are consistent 410 with mounting evidence that infant PFC has remarkably sophisticated function despite structural 411 immaturity [122]. Prior studies have reported activity in lateral PFC that corresponds to adult 412 functional organization. For example, a region in lateral PFC in infants responds more to sequences 413 with statistical regularity compared to unstructured input [123-125]. Another area in infant PFC 414 responds more to native language compared to foreign language or other non-speech sounds [126415 130] and putative language areas have highly specific connection with orthographic-specific 416 perceptual regions in VTC [131]. Thus, Werchan and Amso [132] have argued that PFC function is 417 not immature in infants, but functions adaptively for infants' age-specific ecological niche; Deheane418 Lambertz and Spelke [133] argued for PFC as key player in infant cognitive development; and Saygin 419 and colleagues $[131,134]$ have argued that long-range structurally connectivity with PFC constrains

420 functional development. Our current results provide further evidence in favor of such views, 421 incorporating the social functions of MPFC as well.

\section{Summary}

423 In sum, using fMRI in awake human infants, we find that in addition to visual perception 424 regions, the STS and MPFC also have face-selective responses early in infancy. These results suggest 425 that human infant brains not only perceive faces as a special class of objects, but also process faces 426 as self-relevant potential social partners. Our findings about the origins of face selectivity accord 427 with a broader theoretical view about the origins of the mind: infants are not passive statisticians 428 analyzing data in a purely data-driven fashion [135], but actively participate in the construction of 429 their own minds, choosing which input to process and hypotheses to test in pursuit of their own 
bioRxiv preprint doi: https://doi.org/10.1101/2021.12.04.471085; this version posted December 5, 2021. The copyright holder for this preprint

(which was not certified by peer review) is the author/funder, who has granted bioRxiv a license to display the preprint in perpetuity. It is made available under aCC-BY-NC-ND 4.0 International license.

430 agenda. The social value of faces may thus be reflected in the order and timing of development of 431 face-selective responses across multiple regions of the human infant brain. 


\section{Methods}

\section{Subjects}

434 Infants were recruited from the Boston metro area through word-of-mouth, fliers, and social media.

435 Parents of participants were provided parking or, when travel was a constraint for participation,

436 reimbursed travel expenses. Participants received a small compensation for each visit and, whenever

437 possible, printed images of their brain. We recruited 86 infants (2.1-11.9 months; mean age $=5.2$ months; 41 female; 42 Coil 2021) and recovered usable data (see data selection) from 49 infants (Coil 2011, $\mathrm{n}=26,2.5-8.7$ months, 13 female; Coil 2021, $\mathrm{n}=23,2.1-9.7$ months, 11 female). These data were previously used to test if infants have category-selective responses to faces, bodies and scenes in ventral temporal cortex. Results from that investigation are reported in [12].

443 Paradigm 1. Infants watched videos of faces, bodies, objects, and scenes [87], and a colorful, curvy, 444 abstract baseline was used to maintain infants' attention. Videos were selected to be categorically 445 homogeneous within blocks and heterogeneous between blocks. Each block was 18s and was 446 composed of six 3s videos from the same category. Face videos showed one child's face on a black 447 background. Object videos show toys moving. Body videos showed children's hands or feet on a 448 black background. Scene videos showed natural environments. Baseline blocks were also 18s and 449 consisted of six 3s videos that featured abstract color scenes such as liquid bubbles or tie-dyed 450 patterns. Block order was pseudo-random such that all blocks played once prior to playing again. 451 Videos played continuously for as long as the infant was content, paying attention, and awake.

452 Paradigm 2. Infants watched videos from the same five categories (faces, objects, bodies, scenes, 453 curvy baseline) as in Paradigm 1. However, the videos were shortened to $2.7 \mathrm{~s}$, interleaved with still 454 images from the same category (but not drawn from the videos) presented for $300 \mathrm{~ms}$. All blocks 455 were 18s and included 6 videos and 6 images. Video and image order were randomized within 456 blocks and block order was pseudorandom by category. Paradigm 2 contained one additional block 457 depicting hand-object interactions (not included in the present analysis).

\section{Data Collection}

459 Infants were swaddled if possible. A parent or researcher went into the scanner with the infant while 460 a second adult stood outside the bore of the scanner. Infants heard lullabies

461 (https://store.jammyjams.net/products/pop-goes-lullaby-10) for the duration of the scan. For data 462 collected with Coil 2011, lullabies were played over a loudspeaker into the scanning room. For data 463 collected with Coil 2021, lullabies were played through custom infant headphones (Figure 1c). 
Coil 2011. For data collected with Coil 2011 we used similar methods as previously reported [77]. We used a custom 32-channel infant coil designed for a Siemens Trio 3T scanner [83]. We used a quiet EPI with sinusoidal trajectory [84] with 22 near-axial slices (repetition time, $\mathrm{TR}=3 \mathrm{~s}$, echo time, $\mathrm{TE}=43 \mathrm{~ms}$, flip angle $=90^{\circ}$, field of view, $\mathrm{FOV}=192 \mathrm{~mm}$, matrix $=64 \times 64$, slice thickness $=3 \mathrm{~mm}$, slice gap $=0.6 \mathrm{~mm})$. The sinusoidal acquisition sequence caused substantial distortions in the functional images (Figure S2a).

Coil 2021. Infants wore custom infant MR-safe headphones (Figure 1a). Infant headphones attenuated scanner noises and allowed infants to hear the lullabies. An adjustable coil design increased infant comfort and accommodated headphones as well as a variety of head sizes (Figure 1c). The new infant coil and infant headphones designed for a Siemens Prisma 3T scanner enabled the use of an EPI with standard trajectory with 44 near-axial slices (repetition time, $T R=3 \mathrm{~s}$, echo time, $\mathrm{TE}=30 \mathrm{~ms}$, flip angle $=90^{\circ}$, field of view, FOV $=160 \mathrm{~mm}$, matrix $=80 \mathrm{x} 80$, slice thickness $=2 \mathrm{~mm}$, slice gap $=0 \mathrm{~mm}$ ). Functional data collected with Coil 2021 were less distorted (Figure S2b) than data collected with Coil 2011 (Figure S2a).

\section{Data Selection (subrun creation)}

To be included in the analysis, data had to meet criteria for low head motion. Motion criteria are the same as our two previous studies [12,77]. Data were cleaved between consecutive timepoints having more than 2 degrees or mm of motion, creating subruns, which contained at least 24 consecutive lowmotion volumes. All volumes included in a subrun were extracted from the original run data and combined to create a new Nifti file for each subrun. Paradigm files were similarly updated for each subrun. Volumes with greater than 0.5 degrees or $\mathrm{mm}$ of motion between volumes were removed from all analyses. Total data collected and total data included in each analysis from each subject are reported in [12].

Data collected within a 30-day window from a single subject were analyzed as one data point. Subjects had to have at least 5 minutes of low-motion data to be included in the whole brain analysis. For Coil 2011, this procedure resulted in 566.0 minutes of usable data (mean=5.9 minutes, s.d.=11.3) from 27 subjects (mean age $=4.7$ months, s.d. $=1.4 ; n=10$ Paradigm 2). For Coil 2021, this procedure resulted in 514.3 minutes of usable data (mean $=6.5$ minutes, s.d. $=12.6$ ) from 23 subjects (mean age $=5.7$ months, s.d. $=2.1$; all Paradigm 2). Overall, 49 unique individual infants' data were included in whole brain analyses (one subject contributed data to both Coil 2011 and Coil 2021 datasets). 
To be included in the fROI analysis, subjects had to have at least two subruns with at least 96 volumes in each subrun (one to choose voxels and the other to independently extract response magnitudes from the selected voxels). We included subjects in the fROI analysis for whom we had two timepoints and accounted for individual differences by using a subject random effects regressor and an age regressor in our linear mixed effects analyses (see fROI methods). This resulted in a final fROI dataset of 39 total data points from 36 unique individuals (2.5-9.7 months).

\section{$501 \quad$ Preprocessing}

502 Each subrun was processed individually. First, an individual functional image was extracted from the 503 middle of the subrun to be used for registering the subruns to one another for further analysis.

504 Then, each subrun was motion corrected using FSL MCFLIRT. If more than 3 consecutive images

505 had more than $0.5 \mathrm{~mm}$ or 0.5 degrees of motion, there had to be at least 7 consecutive low-motion

506 volumes following the last high-motion volume for those volumes to be included in the analysis.

507 Additionally, each subrun had to have at least 24 volumes after accounting for motion and sleep

508 TRs. Functional data were skull-stripped (FSL BET2), intensity normalized, and spatially smoothed

509 with a 3mm FWHM Gaussian kernel (FSL SUSAN).

\section{Data registration}

511 All subruns were registered within subjects and then each subject was registered to a standard

512 template. First, the middle image of each subrun was extracted and used as an example image for

513 registration. If the middle image was corrupted by motion or distortion, a better image was selected

514 to be the example image. The example image from the middle subrun of the first visit was used as

515 the target image. All other subruns from each subject were registered to that subject's target image

516 using FSL FLIRT. The target image for each subject was then registered to a template image using

517 FSL FLIRT. For data collected with Coil 2011, the template image was the same one used previously

518 [77]. For data collected with Coil 2021, a template image was selected from a single subject from

519 whom we had a high-resolution anatomical image on which to display functional data. Given the

520 distortion of the images and the lack of an anatomical image for each subject, traditional registration

521 tools do not effectively register infant data. As such, we attempted to register each image using a

522 rigid, an affine, and a partial affine registration with FSL FLIRT. The best image registration was

523 selected by eye from the three options and manually tuned using the Freesurfer GUI for the best

524 possible data alignment. Each image took between 2 and 8 hours of human labor to register. Images

525 collected with Coil 2021 were transformed to the anatomical space of the template image for

526 visualization in Figure S2. 


\section{Subject-level Beta and Contrast Maps}

528 Functional data were analyzed with a whole-brain voxel-wise general linear model (GLM) using custom MATLAB scripts. The GLM included 4 condition regressors (faces, scenes, bodies, and objects), 6 motion regressors, a linear trend regressor, and 5 PCA noise regressors PCA noise regressors analogous to GLMDenoise [136]. Condition regressors were defined as a boxcar function for the duration of each condition block (18s). Infant inattention or sleep was accounted for using a single impulse nuisance ('sleep') regressor. The sleep regressor was defined as a boxcar function with a 1 for each TR the infant was not looking at the stimuli, and the corresponding TR was set to 0 for all condition regressors. Boxcar condition and sleep regressors were convolved with an infant hemodynamic response function (HRF) that is characterized by a longer time to peak and deeper undershoot compared to the standard adult HRF [137]. Next, data and all regressors except PCA noise regressors were concatenated across subruns. PCA noise regressors were computed across concatenated data and beta values were computed for each condition in a whole-brain voxel-wise GLM. Subject-level contrast maps were computed as the difference between the face beta and the average of all non-face (bodies, objects, and scenes) betas for each voxel using in-house MATLAB

\section{Group Random Effects Analysis}

544 To test whether there was systematic overlap between areas of activation across subjects, we

545 conducted one group random effects analysis for eligible data collected with each coil. First, subject-

546 level contrast difference (faces - non-face) maps (see data inclusion and subject contrasts above)

547 were transformed to coil-specific template space (see data registration method above). Group

548 random effects analyses were performed using Freesurfer mri_concat and Freesurfer mri_glmfit.

549 Face responses were only considered if they were significantly greater than non-faces and fell within 550 group-constrained parcels (see next section for parcel definition).

551 Parcels / Search Spaces. Due to the distorted nature of the Coil 2011 dataset, we opted to used 552 larger parcels than the standard FFA parcel we used previously [12] in order to include all available

553 data. We created lateral, ventral, STS, MPFC, and subcortical parcels using the Glasser atlas [138].

554 The lateral parcel included Glasser areas LO1, LO2, LO3, V4, V4t and PIT while the ventral parcel 555 included Glasser areas VMV1, VMV2, VMV3, VVC, PHA1, PHA2, PHA3, and FFC. For the STS

556 parcel, we used Glasser areas STSvp, STSva, STSdp, STSda, STV, and for the MPFC parcel we used 557 Glasser areas p24, d32, 9m, and p32. We also used the anatomically defined thalamus, brainstem, 558 and amygdala from MNI space. 


\section{Functional Region of Interest (fROI)}

To determine if cortical responses are face-specific, we utilized a functional region of interest (fROI) approach. Due to the variable amount of data in each subrun for each subject and the impact this could have on reliable parameter estimates from the GLM, we first combined or split subruns to

563 approximately equate the amount of data across subruns within subjects. For example, if a subject

564 had three subruns and the first was 30 volumes, the second was 75 volumes and third was 325

565 volumes, then we concatenated the first two subruns to create one subrun and we split the third subrun into 3 resulting in a total of four subruns with approximately 100 volumes per subrun.

To constrain search areas for voxel selection, we used anatomically defined parcels (see parcels/search spaces) transformed to subject native space. We used an iterative leave-one-subrunout procedure such that data were concatenated across all subruns except one prior to the wholebrain voxel-wise GLM and contrast were computed (described above). The top 5\% most significant voxels for the contrast faces $>$ (bodies + objects + scenes) within an anatomical constraint parcel were selected as the fROI for that subject, and the parameter estimates were extracted from a GLM on the left-out subrun. For all bar plots, beta values were averaged across participants and experiments.

575 a linear mixed effects model. In each region, we had an a priori hypothesis faces would elicit the

576 largest response. So, in each model, we dummy-coded the other three control conditions, to test the

577 hypotheses that the response to each control condition was lower than to the predicted face. Specifically, we fit a model in MATLAB with the expression:

$$
\text { fitlme }(\text { data } \sim \mathrm{f} 1+\mathrm{f} 2+\mathrm{f} 3+\text { age }+ \text { sex }+ \text { motion }+(1 \mid \text { subject })+(1 \mid \text { coil }))
$$

580 where the three dummy-coded condition regressors are f1 (bodies), f2 (objects) and f3 (scenes).

581 Fixed effects parameters of no interest were age, motion, and sex. Motion was the fraction of scrubbed volumes. Subject and coil were each coded as random intercepts for all models. In the Coil 2011 analyses, we also included a fixed effect paradigm parameter ("para") because two slightly different versions of the experimental paradigm were used during data collection. three control conditions was significantly negative, using a t-test. Because predictions are unidirectional, reported p-values are one-tailed. For example, a face parcel was only deemed face-

588 selective if the parameter estimates for the body, object, and scene regressors were significantly 589 negative.

\section{Effects of infant age.}


591 Effect of age on contrast magnitude: One metric of face selectivity is the difference between the

592 response to faces and all other categories (i.e., the contrast value). To determine if the contrast

593 difference between faces and all non-face conditions changed as a function of infant age, we used a

594 linear mixed effects model for each parcel. Contrast values (i.e., face beta - average beta for all non-

595 face conditions) was the dependent variable. The predictor of interest was age. Motion and sex were

596 fixed effects of non-interest. Coil and subject were coded as random effects. 
597 Acknowledgments: This research was carried out at the Athinoula A. Martinos

598 Imaging Center at the McGovern Institute for Brain Research at MIT. The authors thank Nayanika

599 Das and Somaia Saba for help with registrations; Steven Shannon, Atsushi Takahashi, and Boris Keil

600 for technical support; members of Saxe Lab, and members of the Kanwisher Lab for help during

601 recruitment and data collection; the Cambridge Writing Group, and members of the Saxe Lab and

602 Kanwisher Lab for helpful comments on the manuscript; Michelle Hung and Kirsten Lydic for code

603 review; Hannah LeBlanc for all the things; and all the infants and their families. Funding: We

604 gratefully acknowledge support of this project by a National Science Foundation (graduate

605 fellowship to HLK; Collaborative Research Award \#1829470 to MAC), NIH (\#1F99NS124175 to

606 HLK; \#R21-HD090346-02 to RS; \#DP1HD091947 to NK; shared instrumentation grant

607 S10OD021569 for the MRI scanner), the McGovern Institute for Brain Research at MIT, and the

608 Center for Brains, Minds and Machines (CBMM), funded by an NSF STC award (CCF-1231216).

609 Author contributions: HLK and RS designed the study. HLK, LH, and IN collected the data.

610 HLK analyzed the data with input from and supervision by MAC, NK, and RS. HLK, MAC, NK,

611 and RS wrote the manuscript. All authors provided feedback on the final version. 


\section{References}

613 [1] Jayaraman S, Fausey CM, Smith LB. Why are faces denser in the visual experiences of younger than older infants? Dev Psychol 2017;53:38-49. https://doi.org/10.1037/dev0000230.

616 [2] Jayaraman S, Fausey CM, Smith LB. The Faces in Infant-Perspective Scenes Change over the

[3] Fausey CM, Jayaraman S, Smith LB. From faces to hands: Changing visual input in the first two years. Cognition 2016;152:101-7. https://doi.org/10.1016/j.cognition.2016.03.005.

[4] Goren CC, Sarty M, Wu PYK. Visual following and pattern discrimination of face like stimuli by newborn infants. Pediatrics 1975.

[6] Farroni T, Johnson MH, Menon E, Zulian L, Faraguna D, Csibra G. Newborns’ preference for face-relevant stimuli: Effects of contrast polarity. Proc Natl Acad Sci 2005;102:17245-50. https://doi.org/10.1073/pnas.0502205102.

629 [7] Mondloch CJ, Lewis TL, Budreau DR, Maurer D, Dannemiller JL, Stephens BR, et al. Face perception during early infancy. Psychol Sci 1999;10:419-22. https://doi.org/10.1111/1467-

632 [8] Valenza E, Simion F, Cassia VM, Umiltà C. Face Preference at Birth. J Exp Psychol Hum Percept Perform 1996;22:892-903. https://doi.org/10.1037/0096-1523.22.4.892.

[9] Turati C, Simion F, Milani I, Umiltà C. Newborns' preference for faces: what is crucial? Dev Psychol 2002;38:875-82. https://doi.org/10.1037/0012-1649.38.6.875.

[11] Pascalis O, de Schonen S, Morton J, Deruelle C, Fabre-Grenet M. Mother's face recognition by neonates: A replication and an extension. Infant Behav Dev 1995;18:79-85. https://doi.org/10.1016/0163-6383(95)90009-8. to faces, scenes, and bodies in the ventral visual pathway of infants. Curr Biol 2021:1-10. https://doi.org/10.1016/j.cub.2021.10.064. 
[13] Kanwisher N, McDermott J, Chun MM. The Fusiform Face Area: A Module in Human Extrastriate Cortex Specialized for Face Perception. J Neurosci 1997;17:4302-11. https://doi.org/10.1523/JNEUROSCI.17-11-04302.1997.

[14] Gauthier I, Tarr MJ, Moylan J, Skudlarski P, Gore JC, Anderson AW. The fusiform "face area" is part of a network that processes faces at the individual level. J Cogn Neurosci 2000. https://doi.org/10.1162/089892900562165.

[15] Kanwisher N. Functional specificity in the human brain: A window into the functional architecture of the mind. Proc Natl Acad Sci 2010;107:11163-70. https://doi.org/10.1073/pnas.1005062107.

[16] Skerry AE, Saxe R. A common neural code for perceived and inferred emotion. J Neurosci 2014;34:15997-6008. https://doi.org/10.1523/JNEUROSCI.1676-14.2014.

[17] Deen B, Koldewyn K, Kanwisher N, Saxe R. Functional organization of social perception and cognition in the superior temporal sulcus. Cereb Cortex 2015;25:4596-609. https://doi.org/10.1093/cercor/bhv111.

[18] Lieberman MD, Straccia MA, Meyer ML, Du M, Tan KM. Social, self, (situational), and affective processes in medial prefrontal cortex (MPFC): Causal, multivariate, and reverse inference evidence. Neurosci Biobehav Rev 2019;99:311-28. https://doi.org/10.1016/j.neubiorev.2018.12.021.

[19] Powell LJ, Kosakowski HL, Saxe R. Social Origins of Cortical Face Areas. Trends Cogn Sci 2018;22:752-63. https://doi.org/10.1016/j.tics.2018.06.009.

[20] Arcaro MJ, Livingstone MS. On the relationship between maps and domains in inferotemporal cortex. Nat Rev Neurosci 2021. https://doi.org/10.1038/s41583-021-004904.

[21] Ciarrusta J, Dimitrova R, McAlonan G. Early maturation of the social brain: How brain development provides a platform for the acquisition of social-cognitive competence. vol. 254. 1st ed. Elsevier B.V.; 2020. https://doi.org/10.1016/bs.pbr.2020.05.004.

[22] Morton J, Johnson MH. CONSPEC and CONLERN: A two-process theory of infant face recognition. Psychol Rev 1991;98:164-81. https://doi.org/10.1037/0033-295X.98.2.164.

[23] Kanwisher N. Neural events and perceptual awareness. Cognition 2001;79:89-113. https://doi.org/10.1016/S0010-0277(00)00125-6.

[24] Arcaro MJ, Schade PF, Livingstone MS. Universal Mechanisms and the Development of the Face Network: What You See Is What You Get. Annu Rev Vis Sci 2019;5. 
https://doi.org/10.1146/annurev-vision-091718-014917.

[25] Yue X, Robert S, Ungerleider LG. Curvature processing in human visual cortical areas. Neuroimage 2020;222. https://doi.org/10.1016/j.neuroimage.2020.117295.

[26] Yue X, Pourladian IS, Tootell RBH, Ungerleider LG. Curvature-processing network in macaque visual cortex. Proc Natl Acad Sci U S A 2014;111. https://doi.org/10.1073/pnas.1412616111.

[27] Arcaro MJ, Schade PF, Vincent JL, Ponce CR, Livingstone MS. Seeing faces is necessary for face-domain formation. Nat Neurosci 2017;20:1404-12. https://doi.org/10.1038/nn.4635.

[28] Puce A, Allison T, Bentin S, Gore JC, McCarthy G. Temporal cortex activation in humans viewing eye and mouth movements. J Neurosci 1998;18:2188-99. https://doi.org/10.1523/jneurosci.18-06-02188.1998.

[29] Isik L, Koldewyn K, Beeler D, Kanwisher N. Perceiving social interactions in the posterior superior temporal sulcus. Proc Natl Acad Sci 2017;114:E9145-52. https://doi.org/10.1073/pnas.1714471114.

[30] Pernet CR, McAleer P, Latinus M, Gorgolewski KJ, Charest I, Bestelmeyer PEG, et al. The human voice areas: Spatial organization and inter-individual variability in temporal and extratemporal cortices. Neuroimage 2015;119:164-74. https://doi.org/10.1016/j.neuroimage.2015.06.050.

[31] Belin P, Zatorre RJ, Lafaille P, Ahad P, Pike B. Voice-Selective Areas in Human Auditory Cortex. Found Soc Neurosci 2018:309-12. https://doi.org/10.7551/mitpress/3077.003.0023.

[32] Deen B, Saxe R, Kanwisher N. Processing communicative facial and vocal cues in the superior temporal sulcus. Neuroimage 2020;221. https://doi.org/10.1016/j.neuroimage.2020.117191.

[33] Beauchamp MS, Argall BD, Bodurka J, Duyn JH, Martin A. Unraveling multisensory integration: Patchy organization within human STS multisensory cortex. Nat Neurosci 2004;7:1190-2. https://doi.org/10.1038/nn1333.

[34] Harris LT, McClure SM, Van Den Bos W, Cohen JD, Fiske ST. Regions of the MPFC differentially tuned to social and nonsocial affective evaluation. Cogn Affect Behav Neurosci 2007;7:309-16. https://doi.org/10.3758/CABN.7.4.309.

[35] DiNicola LM, Braga RM, Buckner RL. Parallel distributed networks dissociate episodic and social functions within the individual. J Neurophysiol 2020;123:1144-79. 
https://doi.org/10.1152/JN.00529.2019.

[36] Shamay-Tsoory SG, Tomer R, Berger BD, Goldsher D, Aharon-Peretz J. Impaired "affective theory of mind" is associated with right ventromedial prefrontal damage. Cogn Behav Neurol 2005;18:55-67. https://doi.org/10.1097/01.wnn.0000152228.90129.99.

[37] Moran JM, Macrae CN, Heatherton TF, Wyland CL, Kelley WM. Neuroanatomical Evidence for Distinct Cognitive and Affective Components of Self. J Cogn Neurosci 2006;18:1586-94.

[38] D'Argembeau A, Feyers D, Majerus S, Collette F, Van der Linden M, Maquet P, et al. Selfreflection across time: Cortical midline structures differentiate between present and past selves. Soc Cogn Affect Neurosci 2008;3:244-52. https://doi.org/10.1093/scan/nsn020.

[39] D'Argembeau A, Collette F, Van Der Linden M, Laureys S, Del Fiore G, Degueldre C, et al. Self-referential reflective activity and its relationship with rest: A PET study. Neuroimage 2005;25:616-24. https://doi.org/10.1016/j.neuroimage.2004.11.048.

[40] Farb NAS, Segal Z V., Mayberg H, Bean J, Mckeon D, Fatima Z, et al. Attending to the present: Mindfulness meditation reveals distinct neural modes of self-reference. Soc Cogn Affect Neurosci 2007;2:313-22. https://doi.org/10.1093/scan/nsm030.

[41] Jenkins AC, Macrae CN, Mitchell JP. Repetition suppression of ventromedial prefrontal activity during judgments of self and others. Proc Natl Acad Sci U S A 2008;105:4507-12. https://doi.org/10.1073/pnas.0708785105.

[42] Peelen M V., Atkinson AP, Vuilleumier P. Supramodal representations of perceived emotions in the human brain. J Neurosci 2010;30:10127-34. https://doi.org/10.1523/JNEUROSCI.2161-10.2010.

[43] Bruneau E, Dufour N, Saxe R. How We Know It Hurts: Item Analysis of Written Narratives Reveals Distinct Neural Responses to Others' Physical Pain and Emotional Suffering. PLoS One 2013;8. https://doi.org/10.1371/journal.pone.0063085.

[44] Bruneau EG, Pluta A, Saxe R. Distinct roles of the "Shared Pain" and "Theory of Mind" networks in processing others' emotional suffering. Neuropsychologia 2012;50:219-31. https://doi.org/10.1016/j.neuropsychologia.2011.11.008.

[45] Jacoby N, Bruneau E, Koster-Hale J, Saxe R. Localizing Pain Matrix and Theory of Mind networks with both verbal and non-verbal stimuli. Neuroimage 2016. https://doi.org/10.1016/j.neuroimage.2015.11.025.

[46] Shinkareva S V., Gao C, Wedell D. Audiovisual Representations of Valence: a Cross-study Perspective. Affect Sci 2020;1:237-46. https://doi.org/10.1007/s42761-020-00023-9. 
[47] Skerry AE, Saxe R. Neural Representations of Emotion Are Organized around Abstract Event Features. Curr Biol 2015;25:1945-54. https://doi.org/10.1016/j.cub.2015.06.009.

[48] Brody BA, Kinney HC, Kloman AS, Gilles FH. Sequence of central nervous system myelination in human infancy. J Neuropathol Exp Neurol 1987.

[49] Tau GZ, Peterson BS. Normal development of brain circuits. Neuropsychopharmacology 2010;35:147-68. https://doi.org/10.1038/npp.2009.115.

[50] Vasung L, Abaci Turk E, Ferradal SL, Sutin J, Stout JN, Ahtam B, et al. Exploring early human brain development with structural and physiological neuroimaging. Neuroimage 2019;187:226-54. https://doi.org/10.1016/j.neuroimage.2018.07.041.

[51] Smyser CD, Snyder AZ, Neil JJ. Functional connectivity MRI in infants: Exploration of the functional organization of the developing brain. Neuroimage 2011;56:1437-52. https://doi.org/10.1016/j.neuroimage.2011.02.073.

[52] Dubois J, Poupon C, Thirion B, Simonnet H, Kulikova S, Leroy F, et al. Exploring the Early Organization and Maturation of Linguistic Pathways in the Human Infant Brain. Cereb Cortex 2016;26:2283-98. https://doi.org/10.1093/cercor/bhv082.

[53] Johnson MH. Cortical Maturation and the Development of Visual Attention in Early Infancy. J Cogn Neurosci 1990;2:81-95. https://doi.org/10.1162/jocn.1990.2.2.81.

[54] Sydnor VJ, Larsen B, Bassett DS, Alexander-bloch A, Fair DA, Liston C, et al. psychopathology. Neuron 2021:1-27. https://doi.org/10.1016/j.neuron.2021.06.016. cortical surface expansion from birth to 2 years of age. Cereb Cortex 2013;23:2724-33. https://doi.org/10.1093/cercor/bhs265. myelination development in infants, using MR images. Neuroradiology 2004;46:781-6. https://doi.org/10.1007/s00234-004-1241-z. 
772

773

774

775

776

777

778

779

780

781

782

783

784

785

786

787

788

789

790

791

792

793

794

795

796

797

798

799

800

801

802

803

[59] Hasegawa M, Houdou S, Mito T, Takashima S, Asanuma K, Ohno T. Development of myelination in the human fetal and infant cerebrum: A myelin basic protein immunohistochemical study. Brain Dev 1992;14:1-6. https://doi.org/10.1016/S03877604(12)80271-3.

[60] Chugani HT, Phelps ME. Maturational changes in cerebral function in infants determined by 18FDG positron emission tomography. Science (80- ) 1986;231:840-3. https://doi.org/10.1126/science.3945811.

[61] Huttenlocher PR, Dabholkar AS. Regional differences in synaptogenesis in human cerebral cortex. J Comp Neurol 1997;387:167-78. https://doi.org/10.1002/(SICI)10969861(19971020)387:2<167::AID-CNE1>3.0.CO;2-Z.

[62] Sanai N, Nguyen T, Ihrie RA, Mirzadeh Z, Tsai HH, Wong M, et al. Corridors of migrating neurons in the human brain and their decline during infancy. Nature 2011;478:382-6. https://doi.org/10.1038/nature10487.

[63] Kostović I, Sedmak G, Judaš M. Neural histology and neurogenesis of the human fetal and infant brain. Neuroimage 2019;188:743-73. https://doi.org/10.1016/j.neuroimage.2018.12.043.

[64] Bushnell IWR, Sai F, Mullin JT. Neonatal recognition of the mother's face. Br J Dev Psychol 1989;7:3-15. https://doi.org/10.1111/j.2044-835X.1989.tb00784.x.

[65] Field TM, Cohen D, Garcia R, Greenberg R. Mother-stranger face discrimination by the newborn. Infant Behav Dev 1984;7:19-25. https://doi.org/10.1016/S0163-6383(84)80019-3.

[66] Kelly DJ, Quinn PC, Slater AM, Lee K, Gibson A, Smith M, et al. Three-month-olds, but not newborns, prefer own-race faces. Dev Sci 2005;8:31-6. https://doi.org/10.1111/j.14677687.2005.0434a.x.Three-month-olds.

[67] Ramsey-Rennels JL, Langlois JH. Infants' differential processing of female and male faces. Curr Dir Psychol Sci 2006;15:59-62. https://doi.org/10.1111/j.0963-7214.2006.00407.x.

[68] Turati C, Montirosso R, Brenna V, Ferrara V, Borgatti R. A Smile Enhances 3-Month-Olds' Recognition of an Individual Face. Infancy 2011;16:306-17. https://doi.org/10.1111/j.15327078.2010.00047.x.

[69] Bayet L, Quinn PC, Tanaka JW, Lee K, Gentaz É, Pascalis O. Face gender influences the looking preference for smiling expressions in 3.5-month-old human infants. PLoS One 2015;10:6-13. https://doi.org/10.1371/journal.pone.0129812.

[70] Kiley Hamlin J, Wynn K, Bloom P. Three-month-olds show a negativity bias in their social 
804

805

806

807

808

809

810

811

812

813

814

815

816

817

818

819

820

821

822

823

824

825

826

827

828

829

830

831

832

833

834

835

evaluations. Dev Sci 2010;13:923-9. https://doi.org/10.1111/j.1467-7687.2010.00951.x.

[71] Kinzler KD, Dupoux E, Spelke ES. The native language of social cognition. Proc Natl Acad Sci 2007;104:12577-80. https://doi.org/10.1073/pnas.0705345104.

[72] Powell LJ, Spelke ES. Human infants' understanding of social imitation: Inferences of affiliation from third party observations. Cognition 2018;170:31-48. https://doi.org/10.1016/j.cognition.2017.09.007.

[73] Johnson SC, Dweck CS, Chen FS, Stern HL, Ok SJ, Barth M. At the intersection of social and cognitive development: Internal working models of attachment in infancy. Cogn Sci 2010;34:807-25. https://doi.org/10.1111/j.1551-6709.2010.01112.x.

[74] Farroni T, Chiarelli AM, Lloyd-Fox S, Massaccesi S, Merla A, Di Gangi V, et al. Infant cortex responds to other humans from shortly after birth. Sci Rep 2013;3:3-7. https://doi.org/10.1038/srep02851.

[75] Ichikawa H, Kanazawa S, Yamaguchi MK, Kakigi R. Infant brain activity while viewing facial movement of point-light displays as measured by near-infrared spectroscopy (NIRS). Neurosci Lett 2010;482:90-4. https://doi.org/10.1016/j.neulet.2010.06.086.

[76] Powell LJ, Deen B, Saxe R. Using individual functional channels of interest to study cortical development with fNIRS. Dev Sci 2018;21:e12595. https://doi.org/10.1111/desc.12595.

[77] Deen B, Richardson H, Dilks DD, Takahashi A, Keil B, Wald LL, et al. Organization of highlevel visual cortex in human infants. Nat Commun 2017;8:1-10. https://doi.org/10.1038/ncomms13995.

[78] de Heering A, Rossion B. Rapid categorization of natural face images in the infant right hemisphere. Elife 2015;4:1-14. https://doi.org/10.7554/eLife.06564.

[79] Lloyd-Fox S, Begus K, Halliday D, Pirazzoli L, Blasi A, Papademetriou M, et al. Cortical specialisation to social stimuli from the first days to the second year of life: A rural Gambian cohort. Dev Cogn Neurosci 2017;25:92-104. https://doi.org/10.1016/j.den.2016.11.005.

[80] Tzourio-Mazoyer N, De Schonen S, Crivello F, Reutter B, Aujard Y, Mazoyer B. Neural correlates of woman face processing by 2-month-old infants. Neuroimage 2002;15:454-61. https://doi.org/10.1006/nimg.2001.0979.

[81] Grossmann T, Johnson MH, Lloyd-Fox S, Blasi A, Deligianni F, Elwell C, et al. Early cortical specialization for face-to-face communication in human infants. Proc R Soc B Biol Sci 2008;275:2803-11. https://doi.org/10.1098/rspb.2008.0986.

[82] Krol KM, Grossmann T. Impression Formation in the Human Infant Brain. Cereb Cortex 
Commun 2020:1-11. https://doi.org/10.1093/texcom/tgaa070.

[83] Keil B, Alagappan V, Mareyam A, McNab JA, Fujimoto K, Tountcheva V, et al. Sizeoptimized 32-channel brain arrays for 3 T pediatric imaging. Magn Reson Med 2011;66:177787. https://doi.org/10.1002/mrm.22961.

[84] Zapp J, Schmitter S, Schad LR. Sinusoidal echo-planar imaging with parallel acquisition technique for reduced acoustic noise in auditory fMRI. J Magn Reson Imaging 2012;36:5818. https://doi.org/10.1002/jmri.23699.

[85] Ghotra A, Kosakowski HL, Takahashi A, Etzel R, May MW, Scholz A, et al. A size-adaptive 32-channel array coil for awake infant neuroimaging at 3 Tesla MRI. Magn Reson Med 2021;86:1773-85. https://doi.org/10.1002/mrm.28791.

[86] Cousineau D. Confidence intervals in within-subject designs: A simpler solution to Loftus and Masson's method. Tutor Quant Methods Psychol 2005;1:42-5.

[87] Pitcher D, Dilks DD, Saxe RR, Triantafyllou C, Kanwisher N. Differential selectivity for dynamic versus static information in face-selective cortical regions. Neuroimage 2011;56:2356-63. https://doi.org/10.1016/j.neuroimage.2011.03.067.

[88] Adamson LB, Frick JE. The still face: A history of a shared experimental paradigm. Infancy 2003;4:451-73. https://doi.org/10.1207/S15327078IN0404_01.

[89] Toda S, Fogel A. Infant response to the still-face situation at 3 and 6 months. Dev Psychol 1993;29:532-8. https://doi.org/10.1037/0012-1649.29.3.532.

[90] Lloyd-Fox S, Blasi A, Everdell N, Elwell CE, Johnson MH. Selective cortical mapping of biological motion processing in young infants. J Cogn Neurosci 2011;23:2521-32. https://doi.org/10.1162/jocn.2010.21598.

[91] Lloyd-Fox S, Blasi A, Volein A, Everdell N, Elwell CE, Johnson MH. Social perception in infancy: A near infrared spectroscopy study. Child Dev 2009;80:986-99. https://doi.org/10.1111/j.1467-8624.2009.01312.x.

[92] Poulin-Dubois D, Crivello C, Wright K. Biological motion primes the animate/inanimate distinction in infancy. PLoS One 2015;10:1-12. https://doi.org/10.1371/journal.pone.0116910.

[93] Powell LJ, Spelke ES. Human infants' understanding of social imitation: Inferences of affiliation from third party observations. Cognition 2018;170:31-48. https://doi.org/10.1016/j.cognition.2017.09.007.

[94] Hamlin JK, Wynn K, Bloom P. Social evaluation by preverbal infants. Nature 2007;450:557- 
9. https://doi.org/10.1038/ nature06288.

[95] Liu S, Spelke ES. Six-month-old infants expect agents to minimize the cost of their actions. Cognition 2017;160:35-42. https://doi.org/10.1016/j.cognition.2016.12.007.

[96] Baker RK, Pettigrew TL, Poulin-Dubois D. Infants' ability to associate motion paths with object kinds. Infant Behav Dev 2014;37:119-29. https://doi.org/10.1016/j.infbeh.2013.12.005.

[97] Lisboa IC, Queirós S, Miguel H, Sampaio A, Santos JA, Pereira AF. Infants' cortical processing of biological motion configuration - A fNIRS study. Infant Behav Dev 2020. https://doi.org/10.1016/j.infbeh.2020.101450.

[98] Farroni T, Menon E, Rigato S, Johnson MH. The perception of facial expressions in newborns. Eur J Dev Psychol 2007;4:2-13. https://doi.org/10.1080/17405620601046832.

[99] Addabbo M, Longhi E, Marchis IC, Tagliabue P, Turati C. Dynamic facial expressions of emotions are discriminated at birth. PLoS One 2018;13:1-11. https://doi.org/10.1371/journal.pone.0193868.

[100] Quinn PC, Uttley L, Lee K, Gibson A, Smith M, Slater AM, et al. Infant preference for female faces occurs for same- but not other-race faces. J Neuropsychol 2008;2:15-26. https://doi.org/10.1348/174866407X231029.

[101] Quinn PC, Yahr J, Kuhn A, Slater AM, Pascalis O. Representation of the Gender of Human Faces by Infants: A Preference for Female. Perception 2002;31:1109-21. https://doi.org/10.1068/p3331.

[102] Ramsey JL, Langlois JH, Marti NC. Infant categorization of faces: Ladies first. Dev Rev 2005;25:212-46. https://doi.org/10.1016/j.dr.2005.01.001.

[103] Tham DSY, Bremmer JG, Hay D. In Infancy the Timing of Emergence of the Other-RaceEffect is Dependent on Face Gender. Infant Behav Dev 2015;40:131-8.

[104] Liu S, Xiao NG, Quinn PC, Zhu D, Ge L, Pascalis O, et al. Asian infants show preference for own-race but not other-race female faces: The role of infant caregiving arrangements. Front Psychol 2015;6:1-8. https://doi.org/10.3389/fpsyg.2015.00593.

[105] Mehr SA, Song LA, Spelke ES. For 5-Month-Old Infants, Melodies Are Social. Psychol Sci 2016;27:486-501. https://doi.org/10.1177/0956797615626691.

[106] Bayet L, Perdue KL, Behrendt HF, Richards JE, Westerlund A, Cataldo JK, et al. Neural responses to happy, fearful and angry faces of varying identities in 5- and 7-month-old infants. Dev Cogn Neurosci 2021;47:100882. https://doi.org/10.1016/j.dcn.2020.100882. 
[107] Nakato E, Otsuka Y, Kanazawa S, Yamaguchi MK, Kakigi R. Distinct differences in the pattern of hemodynamic response to happy and angry facial expressions in infants - A nearinfrared spectroscopic study. Neuroimage 2011;54:1600-6. https://doi.org/10.1016/j.neuroimage.2010.09.021.

[108] Saito Y, Aoyama S, Kondo T, Fukumoto R, Konishi N, Nakamura K, et al. Frontal cerebral blood flow change associated with infant-directed speech. Arch Dis Child Fetal Neonatal Ed 2007;92. https://doi.org/10.1136/adc.2006.097949.

[109] Kotilahti K, Nissilä I, Näsi T, Lipiäinen L, Noponen T, Meriläinen P, et al. Hemodynamic responses to speech and music in newborn infants. Hum Brain Mapp 2010;31:595-603. https://doi.org/10.1002/hbm.20890.

[110] Sato H, Hirabayashi Y, Tsubokura H, Kanai M, Ashida T, Konishi I, et al. Cerebral hemodynamics in newborn infants exposed to speech sounds: A whole-head optical topography study. Hum Brain Mapp 2012;33:2092-103. https://doi.org/10.1002/hbm.21350.

[111] Jönsson EH, Kotilahti K, Heiskala J, Wasling HB, Olausson H, Croy I, et al. Affective and non-affective touch evoke differential brain responses in 2 -month-old infants. Neuroimage 2018;169:162-71. https://doi.org/10.1016/j.neuroimage.2017.12.024.

[112] Báez-Mendoza R, Mastrobattista EP, Wang AJ, Williams ZM. Social agent identity cells in the prefrontal cortex of interacting groups of primates. Science (80- ) 2021;374. https://doi.org/10.1126/science.abb4149.

[113] Haber SN, Knutson B. The reward circuit: Linking primate anatomy and human imaging. Neuropsychopharmacology 2010;35:4-26. https://doi.org/10.1038/npp.2009.129.

[114] Pastor V, Medina JH. Medial prefrontal cortical control of reward- and aversion-based behavioral output: Bottom-up modulation. Eur J Neurosci 2021;53:3039-62. https://doi.org/10.1111/ejn.15168.

[115] Bhanji JP, Delgado MR. The social brain and reward: Social information processing in the human striatum. Wiley Interdiscip Rev Cogn Sci 2014;5:61-73. https://doi.org/10.1002/wcs.1266.

[116] Della Longa L, Gliga T, Farroni T. Tune to touch: Affective touch enhances learning of face identity in 4-month-old infants. Dev Cogn Neurosci 2019;35:42-6. https://doi.org/10.1016/j.dcn.2017.11.002.

[117] Della Longa L, Carnevali L, Patron E, Dragovic D, Farroni T. Psychophysiological and 
Visual Behavioral Responses to Faces Associated with Affective and Non-affective Touch in Four-month-old Infants. Neuroscience 2021;464:67-78. https://doi.org/10.1016/j.neuroscience.2020.07.053.

[118] Naoi N, Minagawa-Kawai Y, Kobayashi A, Takeuchi K, Nakamura K, Yamamoto J ichi, et al. Cerebral responses to infant-directed speech and the effect of talker familiarity. Neuroimage 2012;59:1735-44. https://doi.org/10.1016/j.neuroimage.2011.07.093.

[119] Sowell ER, Peterson BS, Thompson PM, Welcome SE, Henkenius AL, Toga AW. Mapping cortical change across the human life span. Nat Neurosci 2003;6:309-15. https://doi.org/10.1038/nn1008.

[120] Casey BJ, Jones RM, Hare TA. The Adolescent Brain. Ann N Y Acad Sci 1008;1124:111-26.

[121] Casey BJ, Trainor RJ, Orendi JL, Schubert AB, Nystrom LE, Giedd JN, et al. A developmental functional MRI study of prefrontal activation during performance of a GoNo-Go task. J Cogn Neurosci 1997;9:835-47. https://doi.org/10.1162/jocn.1997.9.6.835.

[124] Ellis CT, Skalaban LJ, Yates TS, Turk-Browne NB. Attention recruits frontal cortex in human infants. Proc Natl Acad Sci U S A 2021;118. https://doi.org/10.1073/pnas.2021474118.

[125] Gervain J, Macagno F, Cogoi S, Peña M, Mehler J. The neonate brain detects speech structure. Proc Natl Acad Sci U S A 2008;105:14222-7. https://doi.org/10.1073/pnas.0806530105.

[126] Dehaene-Lambertz G, Montavont A, Jobert A, Allirol L, Dubois J, Hertz-Pannier L, et al. Language or music, mother or Mozart? Structural and environmental influences on infants' language networks. Brain Lang 2010;114:53-65. https://doi.org/10.1016/j.bandl.2009.09.003.

[127] Vouloumanos A, Hauser MD, Werker JF, Martin A. The tuning of human neonates' preference for speech. Child Dev 2010;81:517-27. https://doi.org/10.1111/j.14678624.2009.01412.x. 
[129] Altvater-Mackensen N, Grossmann T. Modality-independent recruitment of inferior frontal cortex during speech processing in human infants. Dev Cogn Neurosci 2018;34:130-8. https://doi.org/10.1016/j.dcn.2018.10.002.

[130] May L, Byers-Heinlein K, Gervain J, Werker JF. Language and the newborn brain: Does prenatal language experience shape the neonate neural response to speech? Front Psychol 2011;2:1-9. https://doi.org/10.3389/fpsyg.2011.00222.

[131] Li J, Osher DE, Hansen HA, Saygin ZM. Innate connectivity patterns drive the development of the visual word form area. Sci Rep 2020;10:1-12. https://doi.org/10.1038/s41598-02075015-7.

[132] Werchan DM, Amso D. A Novel Ecological Account of Prefrontal Cortex Functional Development. Physchol Rev 2017;124:720-39.

[133] Dehaene-Lambertz G, Spelke ES. The Infancy of the Human Brain. Neuron 2015;88:93-109. https://doi.org/10.1016/j.neuron.2015.09.026.

[134] Saygin ZM, Osher DE, Norton ES, Youssoufian DA, Beach SD, Feather J, et al. Neurosci 2016;19:1250-5. https://doi.org/10.1038/nn.4354.

[135] Dweck CS. From needs to goals and representations: Foundations for a unified theory of motivation, personality, and development. Psychol Rev 2017;124:689-719. https://doi.org/10.1037/rev0000082. modal parcellation of human cerebral cortex. Nature 2016;536:171-8.

993 https://doi.org/10.1038/nature18933. 


\section{Supplemental Figures and Tables}

997

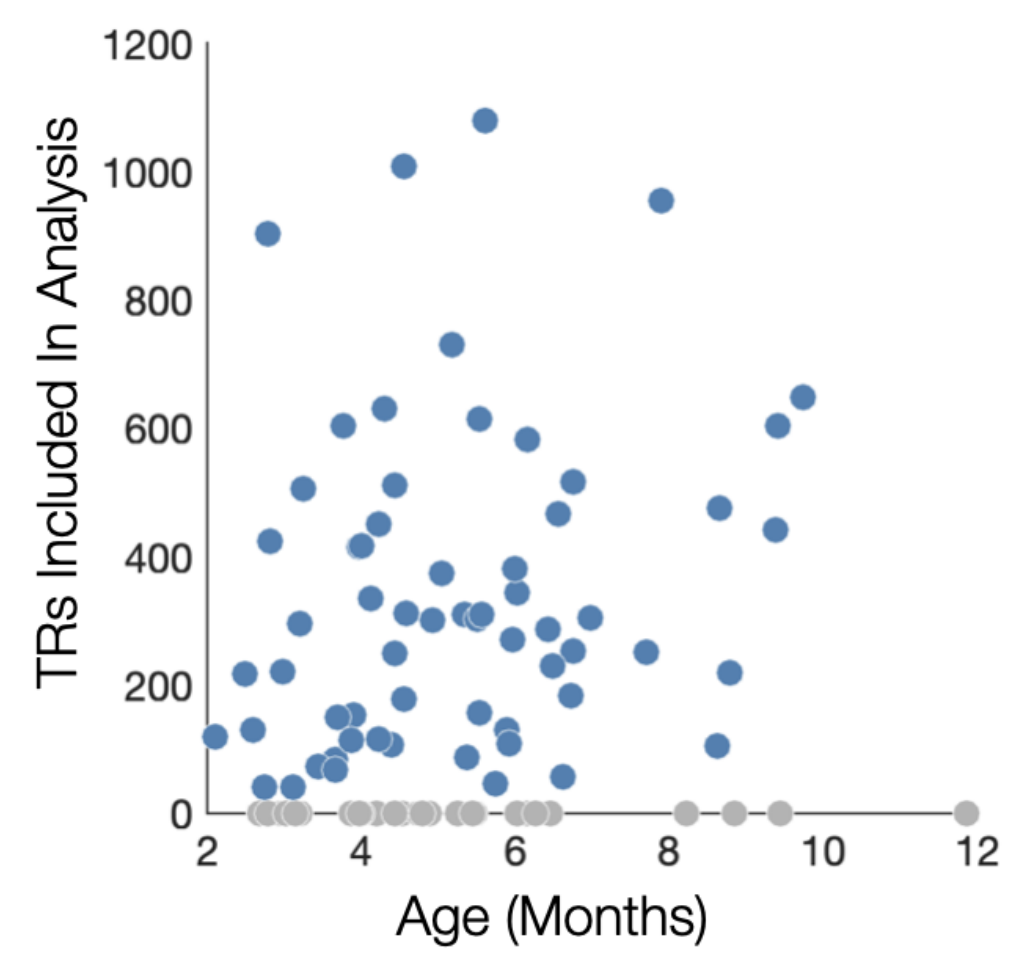

Figure S1. Quantity of low-motion TRs is not correlated with age. The amount of data included for an individual data point was not correlated with the age of that subject $(\mathrm{r}=0.19$, $\mathrm{p}=0.12$ ). Each participant that contributed at least some low motion data is indicated by blue circles. Participants that contributed no data are indicated by gray points. 
Coronal
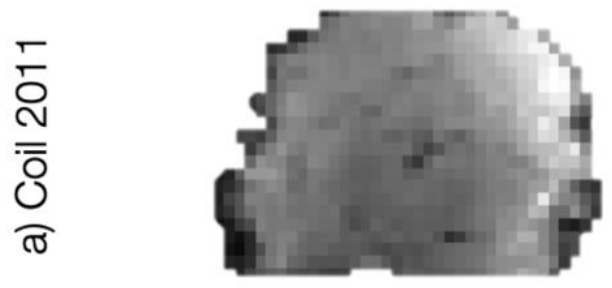

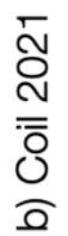

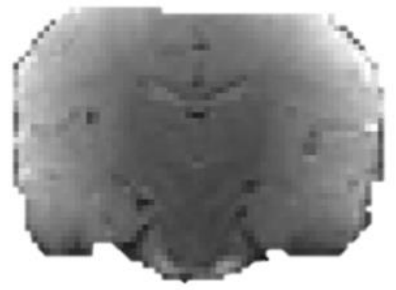

Axial
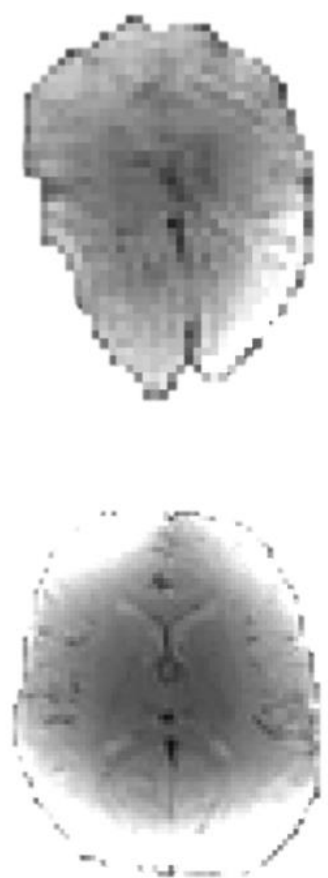

Sagital
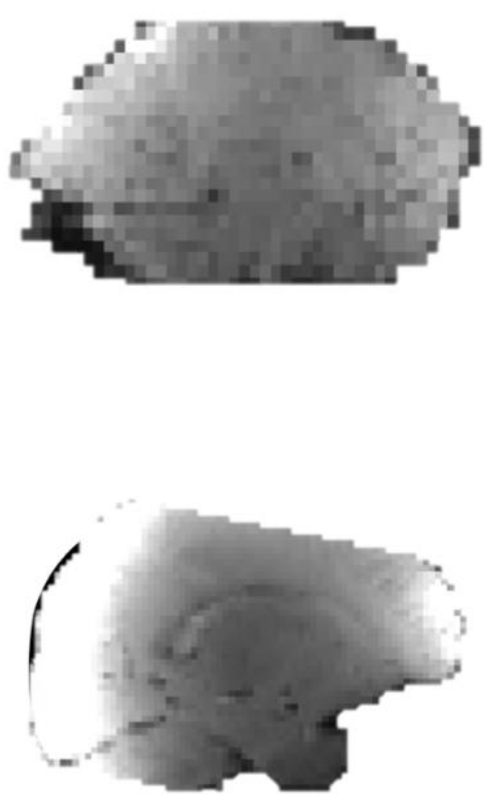

1006

1007

1008

1009

Figure S2. Distortions in infant fMRI data. Representative (not ideal) image of fMRI data collected on Coil 2011 with EPI using a sinusoidal trajectory (a) and an EPI with a standard trajectory collected on Coil 2021 (b). 


\section{Coronal}

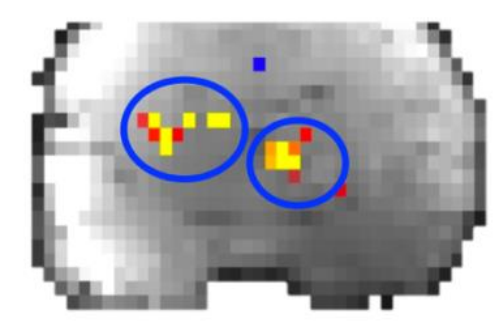

Saggital
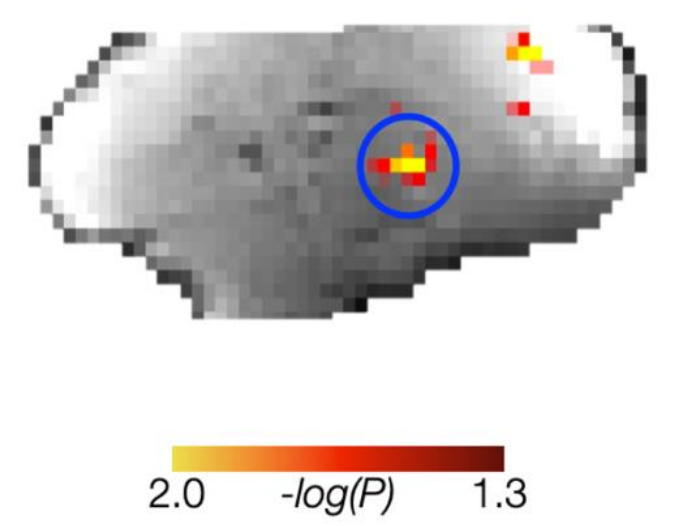

Axial

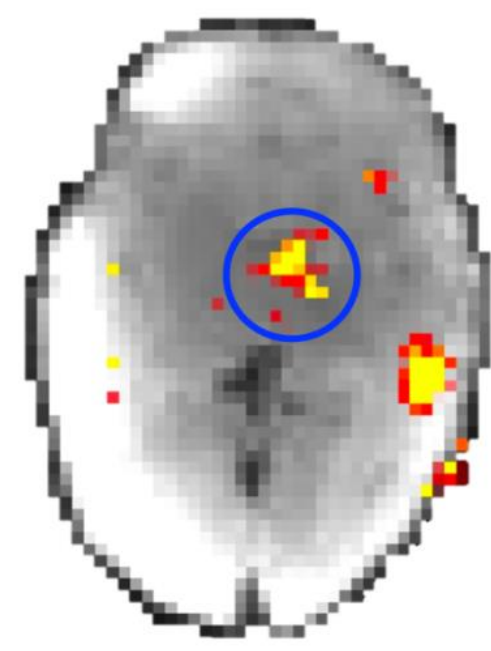

1010

Figure S3. Subcortical responses to faces in Coil 2011 dataset. A group random effects analysis of the Coil 2011 dataset $(n=26)$ revealed a subcortical activation to faces, outlined in blue. These face responses could not be localized to a specific subcortical area due to the distorted nature of the Coil 2011 functional data. 


\section{a) Cortical and Subcortical tSNR for Coil 2021 Dataset}
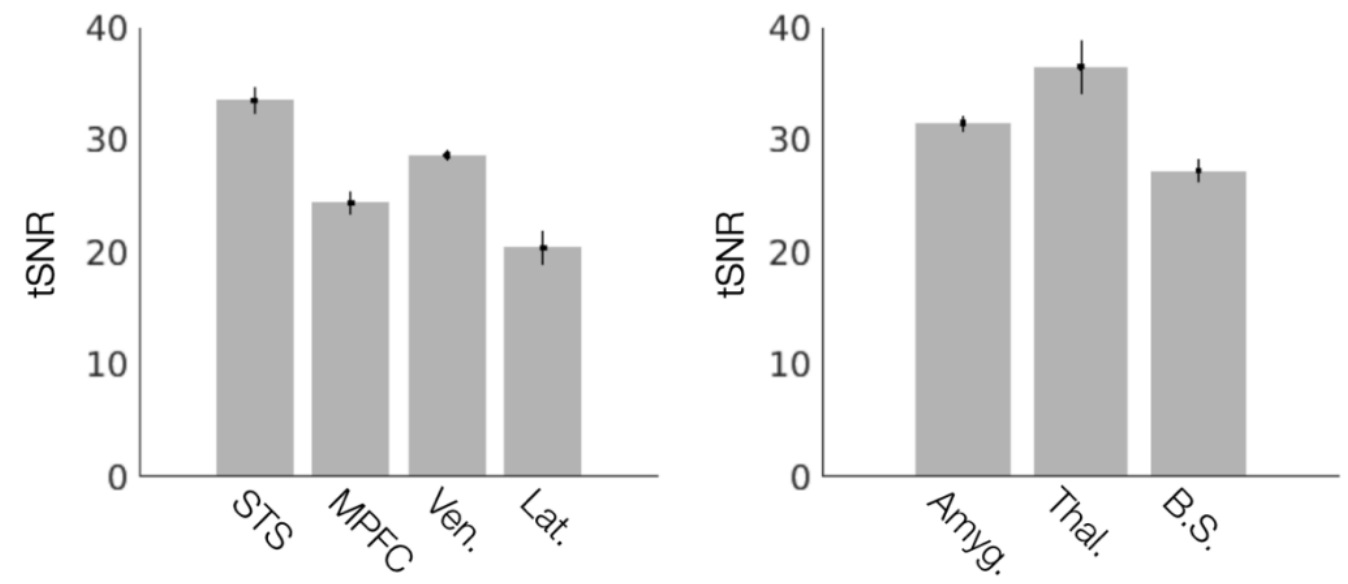

\section{b) Subjects $<5.0$ Months}

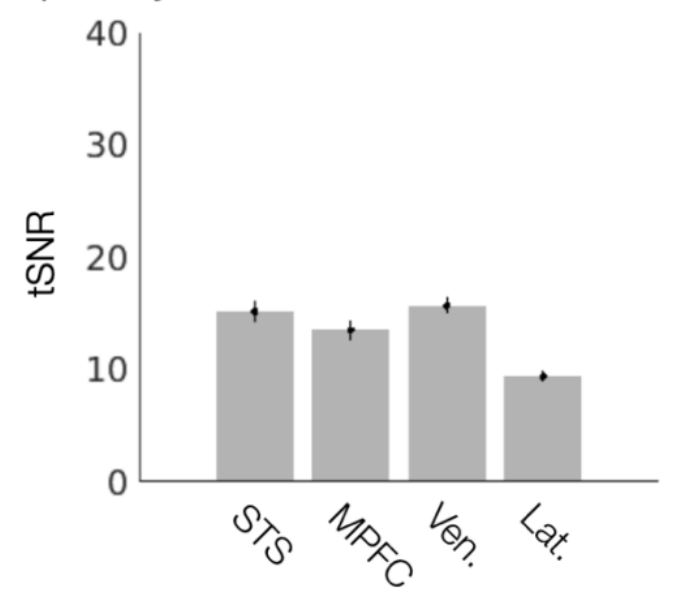

c) Top 10 FFA Subjects

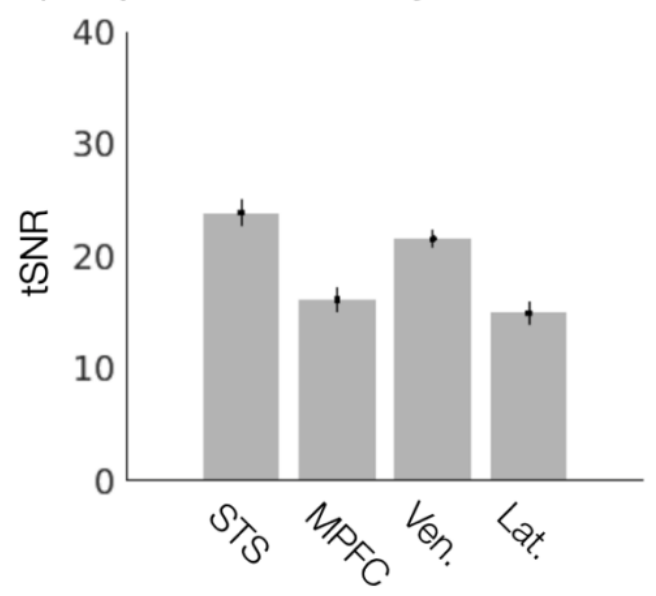

Figure S4. Temporal signal to noise (tSNR) in subsets of data. (a) tSNR across Coil 2021 subjects in cortical (left) and subcortical (right) parcels. (b) tSNR for the youngest subjects across cortical parcels. (c) tSNR in cortical parcels for the 10 subjects with the most face selective responses. Error bars indicate within-subject SE. 


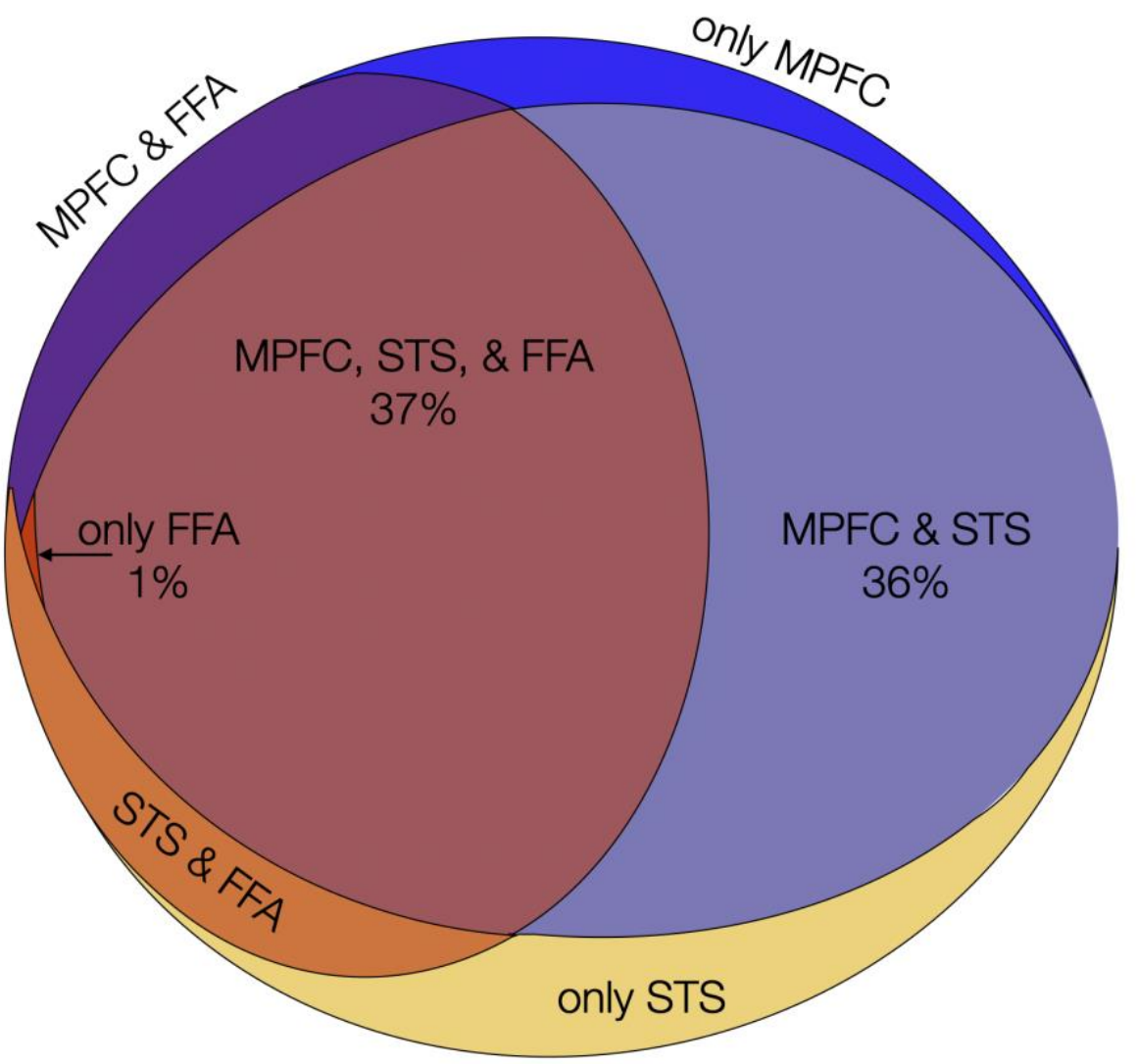
responses in only FFA. Proportional Venn Diagram reveals the number of permutations out of 2500 that MPFC (blue), STS (yellow), and FFA (red) exhibited face-selective responses with overlapping observations represented by merged colors. 
1027 Table S1. Parameter estimates for face-selective responses.

\begin{tabular}{|c|c|c|c|c|c|c|c|c|}
\hline Coil 2011 & Intercept ${ }^{¥}$ & Age $^{¥}$ & Sex & Motion ${ }^{¥}$ & Paradigm $^{\ddagger}$ & F-B ${ }^{¥}$ & F-O $¥$ & F-S $¥$ \\
\hline STS & $\begin{array}{r}0.15 \\
0.03-0 .\end{array}$ & $\begin{array}{c}-0.03 \\
(-0.12-0.06)\end{array}$ & $\begin{array}{c}0.04 \\
0.20-0.29)\end{array}$ & $\begin{array}{c}-0.01 \\
(-0.13-0.10)\end{array}$ & $\begin{array}{c}0.06 \\
(-0.17-0.29)\end{array}$ & $\begin{array}{c}-0.16 \\
(-0.31--0.02)\end{array}$ & $\begin{array}{c}-0.16 \\
-0.30--0.02)\end{array}$ & $\begin{array}{c}-0.15 \\
(-0.30--0.01)\end{array}$ \\
\hline MPFC & $\begin{array}{r}0.441 \\
(0.19-( \\
\end{array}$ & $\begin{array}{c}-0.05 \\
(-0.17-0.07) \\
\end{array}$ & $\begin{array}{c}-0.20 \\
(-0.51-0.11) \\
\end{array}$ & $\begin{array}{c}0.18 \\
(0.04-0.33) \\
\end{array}$ & $\begin{array}{c}0.13 \\
(-0.16-0.42) \\
\end{array}$ & $\begin{array}{c}-0.31 \\
(-0.53--0.09) \\
\end{array}$ & $\begin{array}{c}-0.36 \\
(-0.58--0.14) \\
\end{array}$ & $\begin{array}{c}-0.36 \\
(-0.58--0.14) \\
\end{array}$ \\
\hline \multicolumn{9}{|l|}{ Coil 2021} \\
\hline STS & $\begin{array}{c}0.46 \\
(0.27-0.65)\end{array}$ & $\begin{array}{c}0.05 \\
(-0.06-0.16)\end{array}$ & $\begin{array}{c}0.11 \\
(-0.11-0.33)\end{array}$ & $\begin{array}{c}0.17 \\
(0.06-0.28)\end{array}$ & $\mathrm{n} / \mathrm{a}$ & $\begin{array}{c}-0.44 \\
(-0.63--0.25)\end{array}$ & $\begin{array}{c}-0.44 \\
(-0.63--0.25)\end{array}$ & $\begin{array}{c}-0.43 \\
(-0.62--0.25)\end{array}$ \\
\hline MPFC & $\begin{array}{c}0.40 \\
(0.15-0.65)\end{array}$ & $\begin{array}{c}0.08 \\
(-0.07-0.23)\end{array}$ & $\begin{array}{c}0.34 \\
(0.04-0.63)\end{array}$ & $\begin{array}{c}-0.09 \\
(-0.25-0.06)\end{array}$ & $\mathrm{n} / \mathrm{a}$ & $\begin{array}{c}-0.60 \\
(-0.85--0.35)\end{array}$ & $\begin{array}{c}-0.35 \\
(-0.60--0.10)\end{array}$ & $\begin{array}{c}-0.50 \\
(-0.75--0.25)\end{array}$ \\
\hline Amygdala & $\begin{array}{c}0.16 \\
(0.02-0.31)\end{array}$ & $\begin{array}{c}0.03 \\
(-0.06-0.11) \\
\end{array}$ & $\begin{array}{c}-0.11 \\
(-0.28-0.06) \\
\end{array}$ & $\begin{array}{c}0.05 \\
(-0.03-0.14) \\
\end{array}$ & $\mathrm{n} / \mathrm{a}$ & $\begin{array}{c}-0.20 \\
(-0.35--0.05)\end{array}$ & $\begin{array}{c}-0.13 \\
(-0.28-0.02) \\
\end{array}$ & $\begin{array}{c}-0.12 \\
(-0.27-0.03) \\
\end{array}$ \\
\hline Thalamus & $\begin{array}{c}0.08 \\
(0.01-0.15)\end{array}$ & $\begin{array}{c}0.01 \\
(-0.04-0.05)\end{array}$ & $\begin{array}{c}-0.01 \\
(-0.09-0.07)\end{array}$ & $\begin{array}{c}0.01 \\
(-0.03-0.05)\end{array}$ & $\mathrm{n} / \mathrm{a}$ & $\begin{array}{c}-0.07 \\
(-0.14--0.00)\end{array}$ & $\begin{array}{c}-0.08 \\
(-0.15--0.01)\end{array}$ & $\begin{array}{c}-0.04 \\
(-0.11-0.03)\end{array}$ \\
\hline Brainstem & $\begin{array}{c}0.08 \\
(-0.02-0.18)\end{array}$ & $\begin{array}{c}-0.02 \\
(-0.06-0.03) \\
\end{array}$ & $\begin{array}{c}-0.09 \\
(-0.18-0.00) \\
\end{array}$ & $\begin{array}{c}0.03 \\
(-0.02-0.07) \\
\end{array}$ & $\mathrm{n} / \mathrm{a}$ & $\begin{array}{c}-0.05 \\
(-0.18-0.08) \\
\end{array}$ & $\begin{array}{c}-0.10 \\
(-0.23-0.03) \\
\end{array}$ & $\begin{array}{c}0.02 \\
(-0.10-0.15) \\
\end{array}$ \\
\hline \multicolumn{9}{|l|}{ Combined } \\
\hline STS & $\begin{array}{c}0.37 \\
(0.19-0.55)\end{array}$ & $\begin{array}{c}0.03 \\
(-0.05-0.10)\end{array}$ & $\begin{array}{c}0.07 \\
(-0.08-0.23)\end{array}$ & $\begin{array}{c}0.07 \\
(-0.01-0.15)\end{array}$ & $\begin{array}{c}-0.09 \\
(-0.24-0.07)\end{array}$ & $\begin{array}{c}-0.28 \\
(-0.41--0.16)\end{array}$ & $\begin{array}{c}-0.29 \\
(-0.41--0.17)\end{array}$ & $\begin{array}{c}-0.29 \\
(-0.41--0.16)\end{array}$ \\
\hline MPFC & $\begin{array}{c}0.37 \\
(0.10-0.64)\end{array}$ & $\begin{array}{c}0.03 \\
(-0.08-0.14) \\
\end{array}$ & $\begin{array}{c}0.20 \\
(-0.03-0.42)\end{array}$ & $\begin{array}{c}0.01 \\
(-0.10-0.13)\end{array}$ & $\begin{array}{c}-0.03 \\
(-0.25-0.20)\end{array}$ & $\begin{array}{c}-0.42 \\
(-0.60--0.25)\end{array}$ & $\begin{array}{c}-0.34 \\
(-0.51--0.17)\end{array}$ & $\begin{array}{c}-0.41 \\
(-0.59--0.24)\end{array}$ \\
\hline Ventral & $\begin{array}{c}0.12 \\
(-0.05-0.28)\end{array}$ & $\begin{array}{c}0.06 \\
(-0.00-0.13)\end{array}$ & $\begin{array}{c}0.02 \\
(-0.11-0.15)\end{array}$ & $\begin{array}{c}-0.07 \\
(-0.14--0.01)\end{array}$ & $\begin{array}{c}0.10 \\
(-0.04-0.24)\end{array}$ & $\begin{array}{c}-0.29 \\
(-0.43--0.15)\end{array}$ & $\begin{array}{c}-0.19 \\
(-0.33--0.05)\end{array}$ & $\begin{array}{c}-0.28 \\
(-0.41--0.14)\end{array}$ \\
\hline al & $\begin{array}{c}0.26 \\
(-0.08-0.59) \\
\end{array}$ & $\begin{array}{c}-0.09 \\
(-0.23-0.05) \\
\end{array}$ & $\begin{array}{c}-0.17 \\
(-0.44-0.11) \\
\end{array}$ & $\begin{array}{c}-0.13 \\
(-0.27-0.02) \\
\end{array}$ & $\begin{array}{c}0.21 \\
(-0.07-0.49) \\
\end{array}$ & $\begin{array}{c}-0.30 \\
(-0.51--0.08) \\
\end{array}$ & $\begin{array}{c}-0.17 \\
(-0.38-0.0 \\
\end{array}$ & $\begin{array}{c}-0.42 \\
(-0.64--0.21) \\
\end{array}$ \\
\hline
\end{tabular}

¥ Parameter estimates from linear mixed-effects model with confidence interval in parenthesis; $P \leq 0.05$ indicated in bold; intercept is the difference between face videos and baseline videos; motion is the proportion of scrubbed voxels; paradigm indicates which paradigm was used. 
Table S2. Parameter Estimates for Linear Mixed Effects Model of Contrast Value.

\begin{tabular}{|c|c|c|c|c|}
\hline Cortical $^{\dagger}$ & Intercept $^{*}$ & Age $^{¥}$ & $\overline{\operatorname{Sex}^{*}}$ & Motion ${ }^{¥}$ \\
\hline STS & $\begin{array}{c}0.34 \\
(0.09-0.59)\end{array}$ & $\begin{array}{c}0.00 \\
(-0.13-0.13)\end{array}$ & $\begin{array}{c}-0.10 \\
(-0.36-0.16)\end{array}$ & $\begin{array}{c}0.04 \\
(-0.09-0.18)\end{array}$ \\
\hline MPFC & $\begin{array}{c}0.35 \\
(0.13-0.57)\end{array}$ & $\begin{array}{c}0.04 \\
(-0.12-0.20)\end{array}$ & $\begin{array}{c}0.09 \\
(-0.23-0.40)\end{array}$ & $\begin{array}{c}-0.04 \\
(-0.20-0.12)\end{array}$ \\
\hline Ventral & $\begin{array}{c}0.28 \\
(0.07-0.49) \\
\end{array}$ & $\begin{array}{c}0.05 \\
(-0.08-0.19) \\
\end{array}$ & $\begin{array}{c}-0.06 \\
(-0.32-0.21) \\
\end{array}$ & $\begin{array}{c}-0.02 \\
(-0.16-0.11)\end{array}$ \\
\hline Lateral & $\begin{array}{c}0.31 \\
(-0.00-0.63) \\
\end{array}$ & $\begin{array}{c}0.13 \\
(-0.09-0.36) \\
\end{array}$ & $\begin{array}{c}-0.04 \\
(-0.49-0.41) \\
\end{array}$ & $\begin{array}{c}-0.20 \\
(-0.42-0.03) \\
\end{array}$ \\
\hline \multicolumn{5}{|c|}{ Subcortical $^{\dagger}$} \\
\hline Amygdala & $\begin{array}{c}0.20 \\
(-0.01-0.40)\end{array}$ & $\begin{array}{c}0.12 \\
(-0.03-0.28)\end{array}$ & $\begin{array}{c}-0.10 \\
(-0.40-0.20)\end{array}$ & $\begin{array}{c}0.16 \\
(0.00-0.31)\end{array}$ \\
\hline Thalamus & $\begin{array}{c}0.10 \\
(-0.00-0.21)\end{array}$ & $\begin{array}{c}0.04 \\
(-0.03-0.12)\end{array}$ & $\begin{array}{c}-0.07 \\
(-0.23-0.08)\end{array}$ & $\begin{array}{c}0.00 \\
(-0.08-0.08)\end{array}$ \\
\hline Brainstem & $\begin{array}{c}0.05 \\
(-0.07-0.16)\end{array}$ & $\begin{array}{c}0.07 \\
(-0.01-0.16)\end{array}$ & $\begin{array}{c}-0.01 \\
(-0.18-0.16)\end{array}$ & $\begin{array}{c}0.01 \\
(-0.08-0.09)\end{array}$ \\
\hline
\end{tabular}

¥ Parameter estimates from linear mixed-effects model with confidence interval in parenthesis; $P \leq 0.05$ indicated in bold; intercept (int) is the difference between baseline and the contrast value; motion is the proportion of scrubbed voxels.

t Cortical parcels are combined across Coil 2011 and Coil 2021 datasets; Subcortical parcels are the Coil 2011 dataset only. 
1034 Table S3. Results from Linear Mixed Effects Models for subsets of infants.

\begin{tabular}{|c|c|c|c|c|c|c|c|}
\hline Youngest & Intercept $^{*}$ & Age $^{¥}$ & $\operatorname{Sex}^{¥}$ & Motion $^{¥}$ & $\mathbf{B}^{¥}$ & $\mathbf{O}^{\mp}$ & $\mathbf{S}^{¥}$ \\
\hline$\overline{\text { STS }^{\infty}}$ & $\begin{array}{c}0.46 \\
(0.19-0.72)\end{array}$ & $\begin{array}{c}-0.00 \\
(-0.15-0.14)\end{array}$ & $\begin{array}{c}-0.04 \\
(-0.33-0.25)\end{array}$ & $\begin{array}{c}0.07 \\
(-0.08-0.21)\end{array}$ & $\begin{array}{c}-0.40 \\
(-0.59--0.20)\end{array}$ & $\begin{array}{c}-0.34 \\
(-0.54--0.15)\end{array}$ & $\begin{array}{c}-0.36 \\
(-0.55--0.16)\end{array}$ \\
\hline MPFC & $\begin{array}{c}0.18 \\
(-0.22-0.58) \\
\end{array}$ & $\begin{array}{c}-0.11 \\
(-0.33-0.11) \\
\end{array}$ & $\begin{array}{c}0.28 \\
(-0.17-0.73) \\
\end{array}$ & $\begin{array}{c}0.03 \\
(-0.19-0.25) \\
\end{array}$ & $\begin{array}{c}-0.22 \\
(-0.47-0.03) \\
\end{array}$ & $\begin{array}{c}-0.24 \\
(-0.49-0.00)\end{array}$ & $\begin{array}{c}-0.39 \\
(-0.64--0.14) \\
\end{array}$ \\
\hline Ventral & $\begin{array}{c}0.04 \\
(-0.24-0.31) \\
\end{array}$ & $\begin{array}{c}0.10 \\
(-0.02-0.23) \\
\end{array}$ & $\begin{array}{c}0.01 \\
(-0.23-0.25) \\
\end{array}$ & $\begin{array}{c}-0.14 \\
(-0.25--0.02) \\
\end{array}$ & $\begin{array}{c}-0.22 \\
(-0.44--0.01) \\
\end{array}$ & $\begin{array}{c}-0.18 \\
(-0.40-0.04) \\
\end{array}$ & $\begin{array}{c}-0.14 \\
(-0.35-0.08) \\
\end{array}$ \\
\hline Lateral & $\begin{array}{c}0.41 \\
(-0.26-1.07) \\
\end{array}$ & $\begin{array}{c}0.41 \\
(0.19-0.62) \\
\end{array}$ & $\begin{array}{c}-0.43 \\
(-0.84--0.03) \\
\end{array}$ & $\begin{array}{c}-0.18 \\
(-0.37-0.02) \\
\end{array}$ & $\begin{array}{c}-0.12 \\
(-0.49-0.24) \\
\end{array}$ & $\begin{array}{c}0.03 \\
(-0.33-0.40) \\
\end{array}$ & $\begin{array}{c}-0.20 \\
(-0.57-0.16) \\
\end{array}$ \\
\hline \multicolumn{8}{|l|}{ Best FFA $^{\dagger}$} \\
\hline STS & $\begin{array}{c}0.47 \\
(0.15-0.78)\end{array}$ & $\begin{array}{c}0.11 \\
(-0.01-0.24) \\
\end{array}$ & $\begin{array}{c}-0.14 \\
(-0.40-0.12)\end{array}$ & $\begin{array}{c}0.00 \\
(-0.12-0.12)\end{array}$ & $\begin{array}{c}-0.32 \\
(-0.54--0.10)\end{array}$ & $\begin{array}{c}-0.31 \\
(-0.53--0.09) \\
\end{array}$ & $\begin{array}{c}-0.24 \\
(-0.46--0.02) \\
\end{array}$ \\
\hline MPFC & $\begin{array}{c}0.53 \\
(0.17-0.89)\end{array}$ & $\begin{array}{c}0.01 \\
(-0.16-0.17) \\
\end{array}$ & $\begin{array}{c}0.27 \\
(-0.09-0.63) \\
\end{array}$ & $\begin{array}{c}0.18 \\
(0.02-0.33)\end{array}$ & $\begin{array}{c}-0.62 \\
(-0.97--0.27) \\
\end{array}$ & $\begin{array}{c}-0.43 \\
(-0.78--0.08) \\
\end{array}$ & 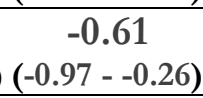 \\
\hline Ventral $^{\dagger}$ & $\begin{array}{c}0.24^{\dagger} \\
(-0.01-0.49)\end{array}$ & $\begin{array}{c}-0.023 \\
(-0.12-0.08) \\
\end{array}$ & $\begin{array}{c}-0.04 \\
(-0.26-0.17)\end{array}$ & $\begin{array}{c}-0.03 \\
(-0.12-0.07)\end{array}$ & $\begin{array}{c}-0.33^{\dagger} \\
(-0.58--0.09) \\
\end{array}$ & $\begin{array}{c}-0.30^{\dagger} \\
(-0.54--0.06) \\
\end{array}$ & $\begin{array}{c}-0.35^{\dagger} \\
(-0.59--0.11) \\
\end{array}$ \\
\hline Lateral & $\begin{array}{c}0.60 \\
(0.20-1.01) \\
\end{array}$ & $\begin{array}{c}-0.12 \\
(-0.32-0.09) \\
\end{array}$ & $\begin{array}{c}-0.51 \\
(-0.95--0.08) \\
\end{array}$ & $\begin{array}{c}-0.27 \\
(-0.45--0.08) \\
\end{array}$ & $\begin{array}{c}-0.18 \\
(-0.51-0.16) \\
\end{array}$ & $\begin{array}{c}-0.31 \\
(-0.64-0.03) \\
\end{array}$ & $\begin{array}{c}-0.39 \\
(-0.72--0.05) \\
\end{array}$ \\
\hline $\begin{array}{l}\text { intercept is the } \\
\text { paradigm indica } \\
{ }^{\infty} \text { For this analy } \\
+ \text { The statistics }\end{array}$ & $\begin{array}{l}\text { es from line } \\
\text { rence betw } \\
\text { which parad } \\
\text { ll infants yc } \\
\text { he Ventral }\end{array}$ & $\begin{array}{l}\text { mixed-effect } \\
\text { face videos } \\
\text { n was used. } \\
\text { ager than } 5.0 \\
\text { cel are circul }\end{array}$ & $\begin{array}{l}\text { s model with ce } \\
\text { and baseline vic } \\
\text { months were se }\end{array}$ & $\begin{array}{l}\text { onfidence inter } \\
\text { deos; motion is } \\
\text { elected ( } 2.5-4.6 \\
\text { set of subjects }\end{array}$ & $\begin{array}{l}\text { al in parenthes } \\
\text { the proportion } \\
\text { months, mean } \\
\text { as chosen bec }\end{array}$ & $\begin{array}{l}\text { is; } P \leq 0.05 \text { ind } \\
\text { of scrubbed } v \\
=3.6 \text { months). } \\
\text { ause they have }\end{array}$ & $\begin{array}{l}\text { icated in bold; } \\
\text { oxels; } \\
\text { the best face- }\end{array}$ \\
\hline
\end{tabular}

